\title{
A RELAÇÃO ENTRE A OROGRAFIA E OS EVENTOS EXTREMOS DE PRECIPITAÇÃO PARA O MUNICÍPIO DE PETRÓPOLIS- RJ
}

\author{
TAVARES, Camila de Moraes Gomes - camila.tardeli.tavares@gmail.com \\ Universidade Federal de Juiz de Fora / UFJF
}

\author{
FERREIRA, Cássia de Castro Martins - cassia.castro@ufjf.edu.br \\ Universidade Federal de Juiz de Fora / UFJF
}

\begin{abstract}
RESUMO: O município de Petrópolis é historicamente marcado por eventos extremos de precipitação que provocam expressivos impactos. Um dos elementos que pode influenciar na distribuição e intensificação dos eventos sobre o município é a localização dele na Serra do Mar Fluminense. Dessa forma, considerações a respeito dos processos e sistemas atmosféricos que atuam sobre áreas ocupadas por cidades edificadas sob relevo acentuado são, sobremaneira, salutares. Considerando tal contexto, o objetivo do presente trabalho foi avaliar, a partir da espacialização dos eventos mais extremos de chuva, a relação desses eventos com a orografia já que, a depender do sistema atmosférico atuante, a orografia pode exercer papel fundamental na distribuição da precipitação, alterando, por conseguinte, as áreas com maiores ou menores volumes de chuva. A partir da análise dos mapas de distribuição da precipitação e hipsométrico, a orografia exerce influência na distribuição espacial das chuvas. Considerando os dados da correlação linear entre as médias dos totais precipitados por evento com as altitudes médias das estações, verificou-se que os eventos 24/12/2010,16/01/2016 e a média do somatório de precipitação que apresentou uma correlação significativa com $R^{2}$ entre 0,81 e 0,99 houve correspondência entre o volume médio precipitado nas áreas de baixa altitude, barlavento e sotavento da Serra do Mar com a média da altitude das áreas onde as estações localizavam-se. $O$ evento de menor correlação foi $13 / 12 / 1981$ com $R^{2}$ de 0,084 , todos os demais eventos apresentaram correlação considerável, uma vez que apresentaram $\mathrm{R}^{2}>0,5$. Destaca-se, ainda que ainda que os sistemas frontais provocaram maiores volumes pluviométricos nas estações à barlavento da serra do mar, enquanto que os sistemas carregadores de umidade provenientes do interior do Brasil foram responsáveis pelos maiores volumes a sotavento.
\end{abstract}

PALAVRAS-CHAVE: Orografia, Evento Extremo, Espacialização, Sistemas Atmosféricos e correlação.

\section{A RELATIONSHIP BETWEEN EROGRAPHY AND EXTREME PRECIPITATION EVENTS FOR PETRÓPOLIS - RJ}

ABSTRACT: The municipality of Petrópolis has historically been marked by extreme precipitation events that cause significant impacts. One of the elements that can influence the distribution and intensification of events over the municipality is its location in the Serra do Mar Fluminense. Thus, considerations regarding the atmospheric processes and systems that act on areas occupied by cities built under accentuated relief are, above all, wholesome. Considering this context, the objective of the present work was to evaluate, from the spatialization of the most extreme rain events, the relationship of these events with the orography since, depending on the atmospheric system, the orography can play a fundamental role in the distribution of precipitation, therefore changing the areas with greater or lesser rainfall. From the analysis of the rainfall distribution and hypsometric maps, the orography influences the spatial distribution of rainfall. Considering the data of the linear correlation between the averages of the total precipitated per event with the average altitudes of the seasons, it was found that the events $12 / 24 / 2010,1 / 16 / 2016$ and the average of the sum of precipitation that showed a significant correlation with $\mathrm{R}^{2}$ between 0.81 and 0.99 there was a correspondence between the average volume precipitated in the low-lying, windward and leeward areas of Serra do Mar with the average altitude of the areas where the stations were located. 
The event with the lowest correlation was $12 / 13 / 1981$ with $R^{2}$ of 0.084 , all other events showed considerable correlation, since they presented $R^{2}>0.5$. It is noteworthy, even though the frontal systems caused greater pluviometry volumes in the windward stations of the Serra do Mar, while the moisture loading systems coming from the interior of Brazil were responsible for the largest leeward volumes

KEYWORDS: Orography, Extreme Event, Spatialization, Atmospheric Systems and correlation.

\section{INTRODUÇÃO}

A compreensão dos fatores que influem nas precipitações em cidades edificadas sob relevo acentuado e com grande variação da declividade é um dos aspectos que depreende sumária atenção, visto que, determinados eventos (como os eventos extremos de chuva) podem, por sua vez, desencadear importantes impactos nos espaços das cidades, podendo esses serem potencializados a depender do sítio urbano. O município de Petrópolis, na Região Serrana do estado do Rio de Janeiro, sofre constantemente com os impactos dos eventos de precipitação como os movimentos de massa e as enchentes. Guerra (2014) destaca que os movimentos de massa são uma das maiores causas de morte por fenômenos naturais no Brasil.

Considerar os impactos da precipitação como fenômenos unicamente naturais é, de certo, um equívoco, já que, o processo de urbanização acelerada e (des) organizado, acaba por criar condições potencializadoras desses impactos. Como bem coloca Monteiro (1991, p.9) "desabamentos de encostas não seriam calamitosos em nossas cidades se parte de seus habitantes não fossem induzidas a formas de urbanização espontânea, precária e em sítios perigosos". Nesse sentido, considerar o sítio urbano sobre o qual cidades são edificadas e recebem as intempéries climáticas é fundamental pois, "o espaço urbano identifica-se a partir do sítio mantendo relações íntimas com o ambiente regional imediato em que se insere" (MONTEIRO, 2003 p.20).

Nesse contexto, uma consideração importante deve ser salientada referente a necessidade de estudos a partir da conexão das partes que é, também, ressaltada por Monteiro (2003,) apresentando que tanto o sítio urbano com suas características quanto a própria dinâmica funcional e a conexão entre ambos são basilares nos estudos sobre a precipitação e seus impactos. Dessa forma, exige-se uma compreensão integrada entre o ambiente urbano e os elementos que o envolve (a ação humana de (re) produção dos espaços); do substrato sob o qual a cidade está edificada (influindo, por sua vez, nas próprias características do clima urbano, uma vez que as vertentes, fundos de vale e afins, ao serem ocupados, influenciarão na dinâmica interna da circulação atmosférica urbana; e o próprio ambiente atmosférico regional (circulação atmosférica regional), já que o relevo pode influenciar diretamente nas variáveis climáticas, à exemplo na distribuição das precipitações sob uma dada área.

Dessa forma, explicita-se a importância de se examinar os fatores geográficos do clima em concomitância com os fenômenos climáticos sobre uma cidade. A partir de tal pressuposto, chama-se atenção, no presente trabalho, para orografia que pode exercer controle sobre a distribuição das chuvas sob uma dada área. Corroborando na discussão a respeito da importância do relevo no controle de variáveis climáticas, Ayoade (1996) discorre que a topografia é um dos fatores que influencia na circulação atmosférica, juntamente com a distribuição das superfícies continentais e oceânicas e as correntes marítimas. 
Cidades edificadas sob relevo acentuado nas condições apresentadas merecem devida atenção como é o caso de Petrópolis que, de acordo com o Atlas Brasileiro de Desastres Naturais (2013), a cidade aparece duas vezes dentre os eventos mais severos que repercutiram em danos humanos (2008 e 2011), ambos os eventos relacionados à precipitação. Dentre os eventos de enxurrada que provocaram mortes a cidade aparece três vezes (2003, 2008 e 2011), além dos eventos de precipitação de 2010 o qual colocou o evento em 70 lugar dentre os piores desastres no estado do Rio de Janeiro que afetou 30 mil citadinos.

Este trabalho tem por objetivo identificar o efeito da orografia e dos sistemas atmosféricos na espacialização das chuvas no município de Petrópolis/RJ já que, a depender do sistema atmosférico atuante, a orografia pode exercer papel fundamental na distribuição da precipitação, alterando, por conseguinte, as áreas com maiores ou menores volumes de chuva

\title{
1.1 CHUVAS OROGRÁFICAS
}

De acordo com Mendonça e Danni-Oliveira (2007, p.71) as chuvas são "classificadas de acordo com sua gênese, que é resultado do tipo de processo que controla os movimentos ascensionais geradores das nuvens das quais se precipitam". Os autores citados classificam as chuvas em: chuvas de origem térmica ou convectivas, chuvas de origem orográfica ou de relevo e chuvas de origem frontal. As chuvas orográficas são resultado da combinação do alto teor de umidade nas camadas mais baixas da atmosfera, típico de regiões costeiras, com o ar quente que tem sua ascensão forçada pela barreira orográfica (SELUCHI e CHOU, 2009 p.67). Mendonça e Danni- Oliveira (2007, p.71) definem as chuvas orográficas como resultado da ação física do relevo que atua como

\begin{abstract}
Barreira à advecção livre do ar, forçando-o a ascender. O ar úmido e quente, ao ascender próximo às encostas, resfria-se adiabaticamente devido à descompreensão promovida pela menor densidade do ar nos níveis mais elevados. O resfriamento conduz a saturação do vapor, possibilitando a formação de nuvens estratiformes e cumuliformes, que, com a continuidade do processo de ascensão tendem a produzir chuva. (MENDONÇA e DANNI-OLIVEIRA, 2007 p.71).
\end{abstract}

Em termos gerais, Ayoade (1996) esclarece que

As montanhas sozinhas [barreiras orográficas], não são muito eficientes para fazer com que a umidade seja removida da massa de ar que se desloca por elas. Todavia, as áreas montanhosas recebem mais precipitação do que os terrenos baixos adjacentes. Além disso, nas vertentes a barlavento das montanhas são conhecidas por receberam mais precipitação dos que as vertentes a sotavento, que são consideradas como sofrendo o efeito de "sombra de chuva" das vertentes a barlavento. (AYOADE, 1996 p.163)

Em termos do grau de influência das barreiras orográficas sobre a precipitação, Ayoade (1996) continua suas colocações apresentando que, tal influência dependerá do tamanho da barreira e do seu alinhamento relativo aos 
eventos portadores de chuva, visto que, as diferentes massas de ar que podem provocar chuva nas áreas de elevação são provenientes de diferentes direções, já que "todas as massas de ar avançam a partir dos seus centros de origem e impõem suas características" (BORSATO e MENDONÇA, 2016 p.3). Deve-se considerar ainda que, "as massas de ar, principalmente aquelas que migram, ou têm por característica expandir a partir de uma área core, sofrem profundas modificações na medida em que se deslocam para áreas com características diferentes de sua área de origem" (BORSATO e MENDONÇA, 2016 p.3). Dessa forma, as massas de ar que adentram o continente e tem sua dinâmica (em termos de força de deslocamento e afins) alterada pela barreira orográfica, faz com que a sua ação nas demais áreas sob a qual atuará, mediante sua energia de deslocamento, seja alterada.

Além do tamanho da barreira e seu alinhamento aos mecanismos atmosféricos, Ayoade (1996, p.163) também chama atenção para a condição de estabilidades atmosférica e para a umidade da massa de ar atuante.

Em uma atmosfera estável a influência orográfica restringe-se a proximidade da montanha ou da escarpa, de maneira que a ação principal do terreno elevado é apenas de redistribuir a precipitação. Por outro lado, quando a atmosfera é instável a orografia tende a aumentar o volume da precipitação bem como distribuí-la por sobre uma área maior (AYOADE, 1996 p.163).

Nesse sentido, pode-se considerar que a orografia apresenta uma dupla função em relação às precipitações, sendo eles, o de barreira que força a subida do ar e, consequentemente a formação de chuvas orográficas, assim elemento atuante na fricção do ar sobre uma dada área influenciando na instabilidade atmosférica.

Reboita (2012) apresenta esquematicamente o modelo de precipitação orográfica ocasionada pela ascensão do ar, condensação e precipitação a barlavento e da descida do ar seco à sotavento (tornando, portanto, essa área mais seca) (Figura 1).

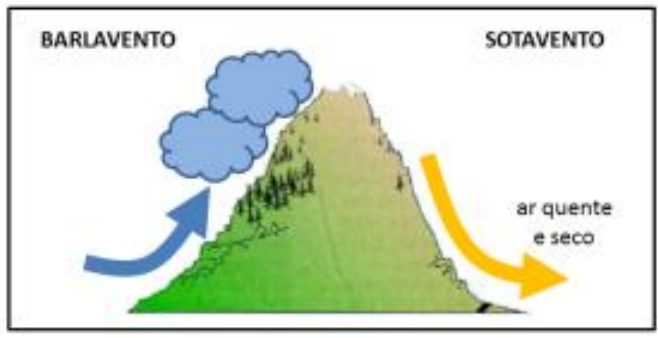

Figura 1 - Esquema representativo de formação de chuvas orográficas. Fonte: REBOITA et. al. (2012)

Blanco (1999, p.5) aponta que "intensificação orográfica da precipitação é muito frequente em regiões costeiras, onde um fator contribuinte é o efeito diferencial da fricção entre o oceano e o continente no campo de divergência, além do fluxo de declive se a costa for montanhosa". A autora apresenta, com base em Smith (1989), três importantes mecanismos responsáveis pela intensificação orográfica, sendo eles: a- Autoconversão (autoconversion) que "resulta da elevação forçada do fluxo de ar pelas vertentes da montanha. Se as condições atmosféricas forem constantes, o crescimento das gotas deverá ser similar em qualquer ponto da montanha, provocando chuva com característica 
temporal uniforme" (MILANESI et. al.,2011 p.69); b- Convecção disparada (triggered convection) "ocorre na vertente mais ensolarada da montanha (leste) em função da quantidade de radiação solar absorvida ao longo do dia, quando nuvens da família dos cumulus, de grande desenvolvimento vertical são ativadas" (MILANESI et. al.,2011 p.69), nesse mecanismo, não há distribuição vertical significativa ao longo da encosta e as árvores apresentam-se como fornecedoras potencial de umidade em elevadas altitudes; c- Semeadoralimentador (daqui por diante designado por seeder-feeder) correspondente à "ocorrência de nuvens mais altas precipitando (seeder) sobre nuvens mais baixas (feeder) ocorrentes pela ascensão da coluna de ar, aumentando a colisão entre as gotas", esse mecanismo pode correr devido à chegada de uma massa de ar sobre, um sistema frontal, por exemplo, a chamada frente fria que libera a precipitação sobre a nebulosidade já pré-existente.

Os estudos sobre a relação do relevo com eventos de precipitação no Brasil são abordados de forma descritiva ao identificar as regiões afetadas sem aprofundamento nos mecanismos físicos responsáveis pelas configurações observadas (BLACO, 1999 p.17). Terassi e Galvani (2017) estudaram o efeito orográfico da Serra do Mar e o potencial erosivo das chuvas nas bacias hidrográficas do Ribeira e Litorânea - Paraná. Para tal estudo, os autores estabeleceram a distribuição espacial da pluviosidade e a estimativa da erosividade das chuvas. Destaca-se que uma das bacias analisadas se localiza a sotavento da serra do mar quanto que a outra a barlavento. Essa distribuição, assim como o potencial erosivo, foi relacionada aos mapas de altitude, evidenciando o padrão de maior volume de precipitação e de erosividade das chuvas à barlavento da serra do mar e menores valores à sotavento.

Roldão et. al. (2012) buscando avaliar a correlação entre altitude, temperatura do ar e precipitação para a Mesorregião Sul e Sudoeste de Minas Gerais e a caracterização do regime climático para essa área, puderam perceber que o maior registro de volume pluviométrico foi verificado na estação de maior altitude concluindo, que houve significativa relação entre o relevo e a distribuição das precipitações. Cândido e Nunes (2008) ao estudarem a influência da orografia na área entre o vale do Rio Tietê e a Serra da Mantiqueira, sazonalmente, observaram que no inverno, as precipitações distribuíram-se mediante a passagem dos mecanismos de mesoescala sobrepondo-se aos fatores locais. Na primavera foi identificada uma ligeira elevação da pluviosidade a partir da zona de Cuestas indicando provável relação com a configuração do relevo. No verão, estação com maiores contrastes na precipitação para área de estudo, foi observado a influência orográfica o que favoreceu a ocorrência de chuvas mais localizadas. No outono, assim como no inverno, a variação da precipitação é pequena, apresentando influência orográfica na sua distribuição.

Forgiarini et. al. (2014), no estudo sobre a análise das chuvas orográficas no estado do Rio Grande do Sul, apresenta que o relevo é um dos principais fatores da heterogeneidade das chuvas no estado. Foi realizado o monitoramento das chuvas a barlavento e sotavento de Silveira Martins. Observaram pluviosidade $9,46 \%$ maior à barlavento em relação as precipitações à sotavento. A correlação entre os totais de precipitação e a altitude foi $77,38 \%$ a barlavento e 93,32\% a sotavento, demonstrando correspondência de relação. Destacam ainda que, os volumes pluviométricos alteravam-se, sendo em alguns episódios a barlavento e em outros a sotavento. 
Para identificarem os motivos dessa variabilidade procuraram observar as imagens de satélite GOES permitindo-Ihes avaliar que, a invasão de massas de ar polar (sudoeste-nordeste) e seu choque com a serra propicia maiores volumes de precipitação a barlavento. Quando a massa de ar se apresenta em sentido noroeste-sudoeste os maiores volumes são a sotavento. Nesse sentido, verifica-se uma alteração entre as vertentes de sotavento e barlavento considerando a ação do sistema atmosférico e sua direção, uma vez que, em ambientes de orografia pronunciada, os volumes pluviométricos serão maiores nas vertentes em que a massa de ar encontra a barreira orográfica.

Em âmbito internacional, Roe (2005) discorre sobre o tema da relação das precipitações coma a orografia partindo desde os primeiros humanos sobre a terra, através das observações em suas migrações sobre diferentes ambientes. Segundo o autor, a precipitação orográfica é um importante aspecto da interação atmosfera-superfície assim, es escalas temporais curtas, os riscos a inundações e movimentos de massa são afetados pela intensidade das precipitações sobre áreas de maior altitude. Uma das formas de avaliar as taxas de precipitação orográfica se dá pela taxa total de condensação em uma coluna vertical de uma atmosfera saturada, onde os níveis de velocidade vertical sejam iguais à elevação orográfica forçada.

Busquet e Smull (2003) apontam como um caminho promissor nos estudos da relação orografia-precipitação, o uso de radares de observação no ar e no solo. Assim, os autores fazem uso de um extenso conjunto de informações de 8 e 21 de outubro de 1999 para investigar uma precipitação orográfica no que tange ao bloqueio de montante do fluxo de ar de baixo nível pelos Alpes europeus ao sul até o norte Mediterrâneo. Segundo os autores, a ocorrência de bloqueio de montanha é um dos principais mecanismos de aprofundamento de modificação dos fluxos de aéreos. Os autores vão ainda indicar que as aferições puramente numéricas podem ser subestimadas ou superestimadas em termos das previsões. Dessa forma, buscam, através das análises dos dados de precipitação de radar examinar mais de perto as estruturas de fluxos de ar e precipitação para compreensão dos impactos (quantidade, localização e tipo de precipitação) do bloqueio orográfico gerado por uma barreira montanhosa.

Essa questão pode ser levantada para área o município de Petrópolis, podendo ser aplicada a todos os demais municípios compreendidos na Serra do Mar, tendo em vista que a alternância entre sotavento e barlavento pode relacionar-se com a origem da massa de ar que atua sobre a região (se vinda do oceano ou sul como é o caso das frentes frias e a massa de ar polar, ou da Amazônia a exemplo da Zona de Convergência do Atlântico Sul).

\subsection{EVENTOS EXTREMOS}

A conceituação dos termos "evento extremo" é por deveras necessária nas pesquisas que tangem ao tema, uma vez que esse conceito varia de pesquisa para pesquisa a depender dos objetivos estabelecidos pelos autores. Dentre os trabalhos que usam o termo, dois principais caminhos são utilizados para conceituá-lo: o estatístico e o qualitativo.

Quanto ao estatístico utilizam-se de equações matemáticas aplicadas à um conjunto de dados para determiná-los e conceituá-los em que são estabelecidos limites de intensidade (definindo o extremo) e/ou analisando a 
frequência de limiares de chuva, utilizando-se da condição raridade para sua determinação/conceituação. A exemplo desse escopo, os trabalhos de Libermann et. al. (2001) que define eventos extremos como eventos nos quais a precipitação diária excede um determinado percentual da média sazonal ou anual; Seneviratne et. al. (2012), no Relatório Especial do IPCC sobre gerenciamento de risco, conceitua evento extremo climático como um evento que é raro, em um dado local ou época do ano, sendo, portanto, mais raro do que o Percentil 10 ou 90; Carvalho et. al. (2002) que considera eventos extremos aqueles em que em um dia apresenta-se com $20 \%$ ou mais do total climatológico sazonal para uma dada região; Silveira (2014) ao trabalhar com eventos extremos de temperatura (frio e quente) faz uma classificação a partir de uma análise estatística estabelecendo tempos de duração do fenômeno.

O segundo caminho utilizado em pesquisas sobre eventos extremos é a consideração qualitativa desses eventos na superfície (considerando o substrato físico da cidade e/ou o impacto social e/ou ambiental). Dentre esses, é valido ressaltar que, o uso da estatística não é excluído, mas é analisado concomitantemente à condição de repercussão/impacto (qualitativo) do evento. Dentre os pesquisadores que buscam essa concomitância, destaca-se Stephenson (2008) que se baseia nos atributos da raridade (frequência com que esse evento ocorre no decorrer da série histórica/ tempo), a duração do evento e a severidade do evento, classificando-os binariamente em raros e não raros; graves e não graves (referindo-se ao impacto na sociedade estando diretamente atrelada a exposição à vulnerabilidade); e, por fim, eventos agudos e não agudos (diretamente ligados à longevidade dos eventos).

Hoffmann et. al. (2014) denomina eventos climáticos extremos (ou hazards) como "resultado de processos naturais, que ocorrem com magnitude fora dos padrões medianos dos fenômenos meteorológicos de uma dada localidade e, quando em contato com a sociedade, decorrem na formação dos riscos e as vulnerabilidades associadas" (HOFFMANN, 2014 p.223). Segundo Nascimento Júnior (2016) os eventos extremos são considerados admitindo tanto a intensidade, velocidade e frequência, quanto a noção de infelicidade (condição qualitativa do evento no que tange ao impacto social e econômico da população afetada). Segundo o autor, ainda que os eventos correspondam à habitualidade, a depender das escalas temporais, esses podem se configurar quanto evento extremo. Nas considerações de Simas (2016) os eventos extremos estão diretamente relacionados a capacidade de resiliência que uma sociedade de um determinado local possui frente aos fenômenos da natureza.

A partir do exposto, o quadro 1 apresenta a discriminação das principais características observadas, a partir da leitura e discussão dos autores citados a cima, do uso de conceito de evento extremo a partir do limiar estatístico e da condição qualitativa. Ressalta-se que, ambas as condições são utilizadas em estudos, como já apontado, estando sempre claros os objetivos que se busca atingir. 
Quadro 1 - Quadro de discriminação das principais características dos eventos extremos estatísticos e qualitativos.

\begin{tabular}{|c|c|}
\hline \multicolumn{2}{|c|}{ Eventos Extremos } \\
\hline Estatísticos & Qualitativos \\
\hline $\begin{array}{c}\text { Definido a partir de um limite } \\
\text { estatístico }\end{array}$ & $\begin{array}{c}\text { Definido a partir da existência } \\
\text { de impacto derivado do evento }\end{array}$ \\
$\begin{array}{c}\text { Uso de equações matemáticas } \\
\text { para conceituar/definir } \\
\text { na definição/ conceituação são } \\
\text { os impactos decorrentes dos } \\
\text { eventos }\end{array}$ \\
$\begin{array}{c}\text { Uso da estatística de forma } \\
\text { basilar }\end{array}$ & $\begin{array}{c}\text { Uso da estatística de forma } \\
\text { auxiliar }\end{array}$ \\
\hline $\begin{array}{c}\text { Estabelecimento de limites de } \\
\text { intensidade de chuvas }\end{array}$ & $\begin{array}{c}\text { Eventos relacionados aos riscos } \\
\text { e vulnerabilidades associados }\end{array}$ \\
\hline $\begin{array}{c}\text { Principais variáveis } \\
\text { consideradas: raridade, } \\
\text { frequência, intensidade, duração variáveis } \\
\text { dos eventos }\end{array}$ & $\begin{array}{c}\text { ponsideradas: impacto social, } \\
\text { econômico, ambiental, } \\
\text { adaptação, noção de } \\
\text { infelicidade }\end{array}$ \\
\hline
\end{tabular}

Destaca-se, portanto, que diferentes são as conceituações de evento extremo e, portanto, devem estar bem esclarecidas nos trabalhos que desejam estuda-los, estando, desse modo, de acordo com os objetivos estabelecidos. 0 presente trabalho visa, portanto, identificar o efeito da orografia e dos sistemas atmosféricos na espacialização das chuvas no município de Petrópolis/RJ. Dessa forma, o presente trabalho faz uso do termo evento estatisticamente extremo, o qual é definido como eventos $\geq P 95$ (percentil) baseado na técnica empregada no trabalho de Pinheiro (2016) e adaptada para a classificação dos extremos.

\subsection{CARACTERIZAÇÃo DA ÁREA}

O município de Petrópolis localiza-se na região Sudeste do Brasil no estado do Rio de Janeiro na porção Sul do estado (Figura 2) caracterizando-se por fazer parte da Serra do Mar Fluminense (Região Serrana do Estado do Rio de Janeiro) entre as coordenadas $43^{\circ} 04^{\prime}-43^{\circ} 14^{\prime} \mathrm{W}$ e $22^{\circ} 33^{\prime} \mathrm{S}$, com altitude média de 845 metros abrangendo área de $811 \mathrm{~km}^{2}$ (GONÇALVES e GUERRA, 2014) (Figura 3). 


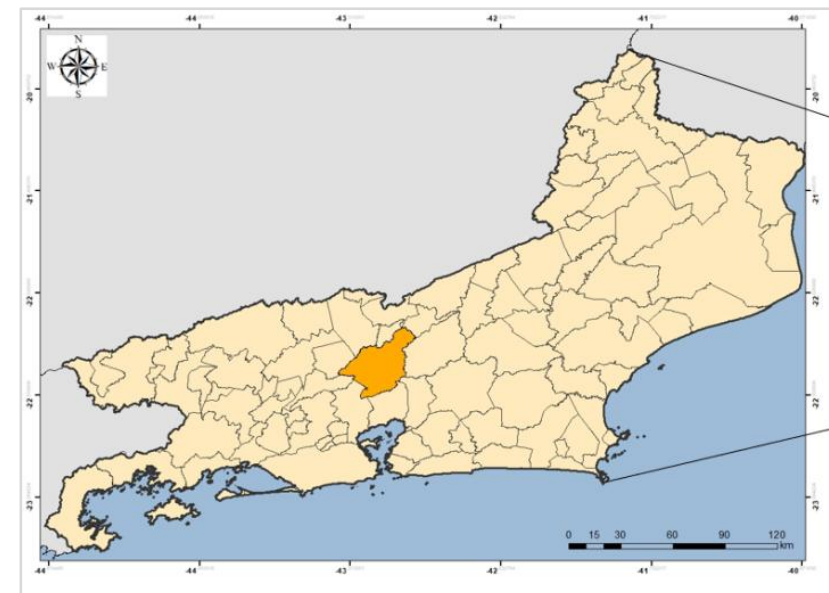

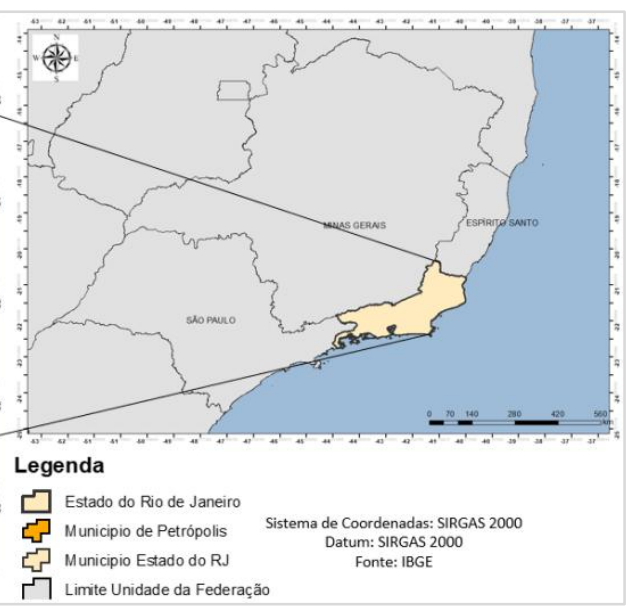

Figura 2 - Mapa de localização da área de estudo

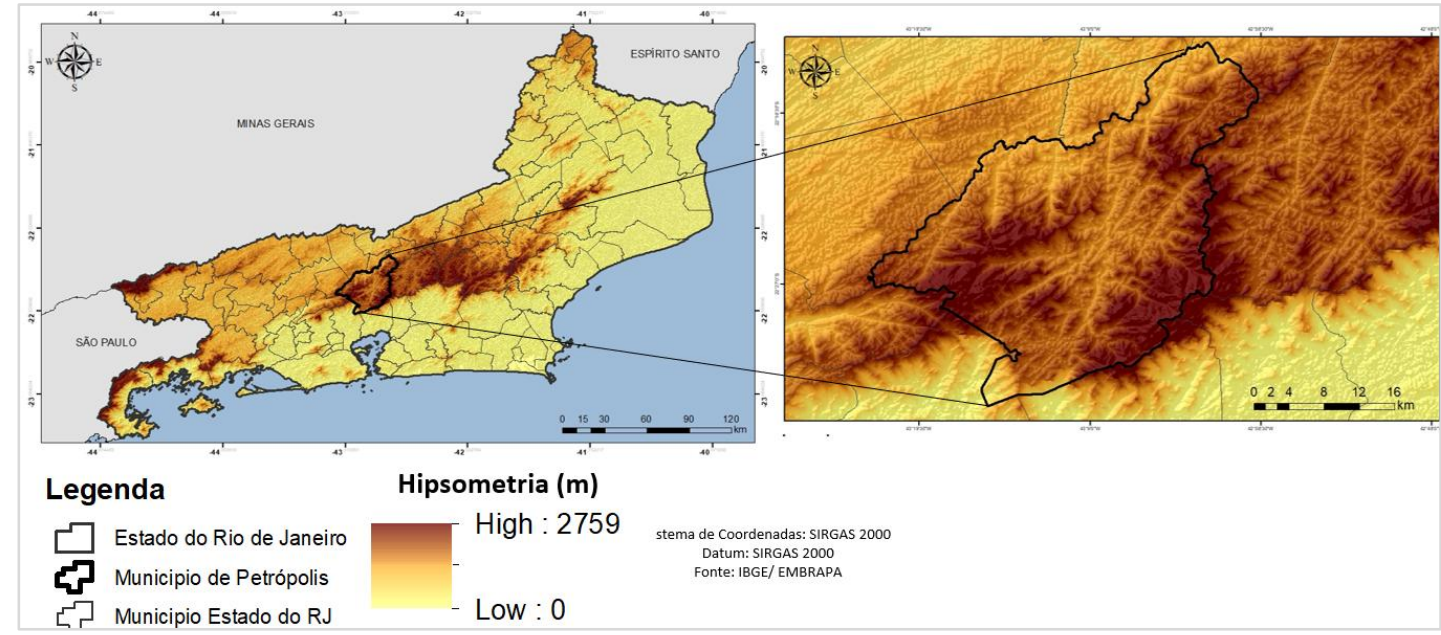

Figura 3 - Mapa hipsométrico do estado do Rio de Janeiro e do Município de Petrópolis

Segundo Nimer (1972) a região Sudeste é a região de maior diversificação climática em termos da temperatura do ar e, maior também de precipitação, estando atrás, apenas da região Nordeste. A topografia da região Sudeste oferece um dos maiores contrates morfológicos do Brasil favorecendo as precipitações "uma vez que ela atua no sentido de aumentar a turbulência do ar pela ascensão orográfica, notadamente durante a passagem de correntes perturbadoras" (NIMER, 1972 p. 6). Em termos da precipitação, a região Sudeste é caracterizada como região cujo regime das chuvas é tipicamente de ritmo tropical onde a Serra do Mar é uma das áreas nitidamente mais chuvosas em função do "trajeto mais frequentado por invasões de correntes de circulação perturbada de Sul, representadas por frente polar; [...] além de estar sob a rota preferida pelas correntes perturbadas de oeste, ou mais precisamente de NW, representadas pelas linhas de IT" (NIMER, 1972 p.22).

Nimer (1972) caracteriza o clima da Cidade de Petrópolis como mesotérmico superúmido, porém no Sudeste possui características tropicais estando mais relacionado às áreas de maior altitude. Uma das características do clima mesotérmico superúmido é a não existência de um período seco e sim 
uma diminuição da umidade, já que não ficam abaixo de $36 \mathrm{~mm}$, limite para considerar uma estação seca (GONÇALVES e GUERRA, 2014 p.219). As chuvas na cidade de Petrópolis concentram-se de outubro a março apresentando maior intensidade no mês de dezembro quando o total pluviométrico chega a $316 \mathrm{~mm}$ ( $15 \%$ chuvas anuais).

A geomorfologia do município de Petrópolis é caracterizada por regiões de Escarpas e Reversos da Serra do Mar inserida na unidade geomorfológica da Serra dos Órgãos (GONÇALVES e GUERRA, 2014)

\begin{abstract}
Essa região apresenta um quadro morfológico relacionado aos efeitos de um tectonismo regional e de sucessivas fases erosionais. Trata-se de uma área resultante de dobramentos, reativação de falhas e remobilização de blocos. A topografia reflete esses condicionamentos geológicos predominantes, em toda sua extensão são registrados vales alongados, segmentos de drenagem retilíneos, maciços graníticos, linhas de cristas e cumeadas paralelas, relevos com grandes desníveis altimétricos, escarpas íngremes e alvéolos intermontanos. (GONÇALVES e GUERRA, 2014 p.233)
\end{abstract}

A vegetação presente no município de Petrópolis corresponde à Mata Atlântica designada pelo projeto RADAM (1983) como Floresta Ombrófila Densa, distribuída por altitude, e reconhecida no município de Petrópolis as Florestas Montanas (ocupam áreas do relevo bastante dissecado e íngreme, encontrada nas faixar de altitude entre 500 e 1500 m, caracterizando-se por presença de estrato arbóreo de $25 \mathrm{~m}$ ); Floresta Submontana (correndo na faixa de altitude entre 50 e 500 m encontrados na serra litorânea, nos maciços isolados e nas encostas sob a influência da massa tropical marítima- ex. Serra os órgãos); Alto Montana (as chamadas matas de altitude localizadas em altitude maiores que $1500 \mathrm{~m}$ sobre rochas do embasamento cristalino, compostas por espécies endêmicas) e Vegetação secundária (correspondente à vegetação surgidas em áreas desmatas da Floresta Ombrófila Densa sendo as capoeiras, capoeirões e capim melado) (GUERRA, 2014).

\title{
2.MATERIAIS E MÉTODOS
}

O presente trabalho foi desenvolvido em 5 etapas:1-levantamento, tratamento dos dados e definição de eventos extremos; 2- aplicação das técnicas; 3- mapeamento; 4- levantamento e análise das cartas sinóticas; 5correlação entre os dados de precipitação e altitude das estações.

\subsection{LEVANTAMENTO, TRATAMENTO DOS DADOS E DEFINIÇÃO DE EVENTOS EXTREMOS}

Primeiramente foram levantados os dados de precipitação diária de 1980-2017 de quatro estações meteorológicas no município de Petrópolis (sendo uma delas localizada na divisa entre o município de Areal) e uma estação localizada no interior do município de Areal (próximo do limite municipal de Petrópolis com 628 metros de distância) sendo essas as cinco estações principais utilizadas na pesquisa. Além das estações principais foram utilizadas outras sete estações complementares para auxilio no processo de interpolação e espacialização dos dados pluviométricos como será destacado adianta. A figura 4 apresenta a localização das estações utilizadas na pesquisa. 


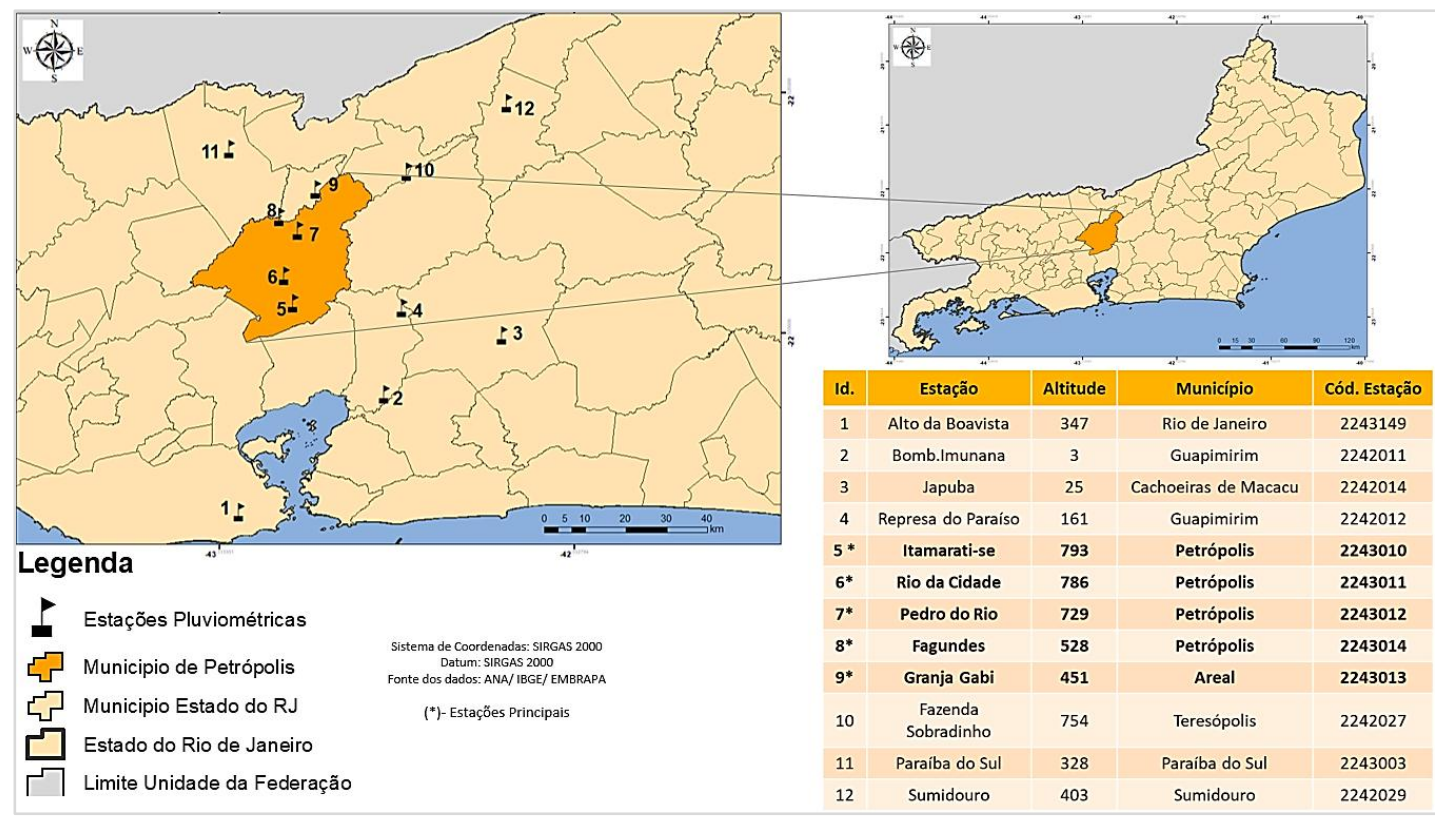

Figura 4 - Mapa de localização das estações principais $(*)$, e complementares com as respectivas informações de altitude, município e código da estação pluviométrica.

Os dados de precipitação foram obtidos a partir da plataforma online da Agência Nacional de Águas (ANA) disponível no link https://www.snirh.gov.br/hidroweb/publico/apresentacao.jsf. Após o download dos dados, foi realizada a sua organização no software Excel. Os dados foram empilhados mês a mês com seus respectivos valores de precipitação diária. Ademais, foram excluídos os valores $<1,0 \mathrm{~mm}$. A tabela 1 apresenta os intervalos com falhas no conjunto de dados utilizados. Para o período em que foi detectada a falha foi feita a exclusão do mês referente do conjunto de dados. Considerando o conjunto de falhas, foi feita a opção pela exclusão dos meses em que houve a ocorrências de falhas no conjunto de dados.

Tabela 1 - Falhas presentes no conjunto de dados das estações principais utilizadas na pesquisa. 


\begin{tabular}{|c|c|}
\hline Itamarati-se & Rio da Cidade \\
\hline Maio, 2017 & 1-3 fevereiro,1997 \\
\hline Setembro, 2017 & Abril, 2008 \\
\hline Dezembro, 1984 & Maio,2003 \\
\hline Dezembro, 2017 & Agosto,2017 \\
\hline Fagundes & Setembro,2017 \\
\hline Janeiro, 1983 & Outubro,2017 \\
\hline 0107 Fevereiro, 1983 & Novembro, 2017 \\
\hline 03-30 abril, 1980 & Dezembro,2017 \\
\hline Maio, 1980 & Pedro do Rio \\
\hline Junho, 1980 & Março, 2015 \\
\hline Julho, 1980 & Agosto, 2017 \\
\hline 01-03 Agosto, 1980 & Novembro, 2017 \\
\hline Agosto, 2017 & Dezembro, 1984 \\
\hline 25- 30 Setembro, 1981 & Areal \\
\hline 1 -16 Outubro, 1981 & Novembro, 2011 \\
\hline 25- 30 Novembro, 1980 & Dezembro, 2000 \\
\hline 16-30 Novembro, 1997 & - \\
\hline Novembro, 2017 & - \\
\hline 01-04 Dezembro, 1980 & - \\
\hline Dezembro, 1984 & - \\
\hline
\end{tabular}

Após o levantamento e organização dos dados, foi dado início a etapa de aplicação da técnica de determinação de eventos estatisticamente extremos. Essa etapa se divide em dois momentos. O primeiro deles é referente à determinação do limiar de precipitação correspondente a eventos de precipitação extrema. Em seguida, foi realizada a classificação dos eventos em: eventos extremos fraco, fraco-moderado, moderado-forte, forte e extremoextremo.

\subsection{APLICAÇÃO DA TÉCNICA DE EXTREMOS E SUAS CLASSIFICAÇõES}

Para 0 estabelecimento de eventos estatisticamente extremos considerou-se o trabalho de Pinheiro (2016) que denomina chuvas extremas os eventos superiores ao Percentil 95. Sendo assim, foram selecionados os dados de precipitação acima de $1 \mathrm{~mm}$ e aplicada a técnica do percentil que, "divide o conjunto de dados em 100 partes, cada uma delas representa um percentual acumulado das observações até aquele limite" (SILVESTRE, 2016 p.98). Essa técnica foi aplicada em cada uma das cinco estações principais estudadas, visto que, a distribuição espacial da chuva não é homogênea em todo o espaço do município. Silvestre (2016, p.98) ressalta a importância de se utilizar as medidas de percentil referenciando-se à Bussab e Morettin (2002), ponderando que "os percentis são medidas robustas, ou seja, seus valores são pouco alterados por mudanças de uma pequena porção dos dados".

Para a classificação dos extremos, foram selecionados apenas os dados iguais ou maiores que o valor obtido a partir da aplicação do P95 (denominando- 
o P195). Após essa nova organização dos dados foi novamente aplicado a técnica do percentil (agora apenas para os valores iguais ou maiores que P95 para cada estação). Foi calculado, portanto, os percentis 85, 90, 95 e 99 (denominando-os de P285, P290, P295, P299) para cada estação permitindo-nos classificar os eventos extremos. A classificação dos eventos a partir dos intervalos percentílicos apresenta-se na tabela 2 . É valido ressaltar que, em cada uma das estações pluviométricas estudadas o valor do limiar que define os eventos enquanto extremos será um, diferenciando das outras estações, isso porque, cada estação possuirá um determinado conjunto de dados, como já exposto.

Tabela 2 - Classificação dos extremos a partir do intervalo percentílico. (1)percentil calculado na primeira etapa; $\left({ }^{2}\right)$ percentil recalculado a partir do P195

Intervalo Percentílico

$\mathrm{P}$ mínimo $\left(\mathrm{P}^{2} 5^{(1)}\right)-\mathrm{P} 85^{(2)}$

$$
\begin{gathered}
P 85^{(2)}-P 90^{(2)} \\
P 90^{(2)}-P 95^{(2)} \\
P 95^{(2)}-P 99^{(2)} \\
>P 99^{(2)}
\end{gathered}
$$

Classificação

Extremo Fraco

Extremo Fraco- Moderado

Extremo Moderado- Forte

Extremo Forte

Extremo Extremo

\subsection{MAPEAMENTOS}

Após a identificação dos eventos mais extremos em cada uma das cinco estações pluviométricas (principais), foi selecionado um evento de classificação extremo-extremo de cada estação para a espacialização. Os eventos extremoextremo representam $5 \%$ dos $5 \%(0,25 \%$ do total de dados do conjunto) sendo, portanto, os maiores valores do conjunto de dados diários, o que pode gerar repercussões espaciais consideráveis uma vez que correspondem aos eventos de maior volume precipitado no decorrer do tempo entre 1980-2017. A tabela 3.a apresenta os limites de intensidade dos extremos pluviométricos para as estações principais utilizadas, a tabela $3 \mathrm{~b}$ apresenta as estações principais com os valores de extremos escolhidos para espacialização. A tabela 3.c apresenta os valores extremos de cada uma das estações com os valores precipitados nas demais estações no município de Petrópolis.

Tabela 3a - Limites de intensidade dos extremos pluviométricos para as estações principais

Itamarati-Se Rio da Cidade Pedro do Rio Granja Gabi Fagundes

\begin{tabular}{l|ccccc} 
P195 & 45,0 & 46,4 & 43,0 & 46,2 & 38,3 \\
P285 & 83,2 & 84,0 & 73,4 & 79,5 & 59,4 \\
P290 & 90,0 & 92,5 & 77,2 & 85,9 & 64,3 \\
P295 & 107,4 & 104,8 & 89,8 & 96,6 & 79,4 \\
P299 & 132,2 & 142,0 & 130,8 & 111,3 & 109,1
\end{tabular}

Tabela 3b - Estações pluviométricas com seus respectivos valores de extremos. Valores em negrito e com $(*)$ correspondem ao evento extremo na estação pluviométrica. 
Rio da Cidade

Pedro do Rio

Granja Gabi

Fagundes
185,8

178,3

160,7

115,6

Tabela 3c - Estações pluviométricas com seus respectivos valores de extremos. Valores em negrito e com $\left(^{*}\right)$ correspondem ao evento extremo na estação pluviométrica.

\begin{tabular}{cccccc} 
Estação & \multicolumn{5}{c}{ Data do Evento Extremo (mm) } \\
\cline { 2 - 6 } Pluviométrica & $13 / 12 / 1981$ & $24 / 12 / 1994$ & $16 / 01 / 2016$ & $24 / 12 / 2010$ & $19 / 01 / 2003$ \\
\hline Itamarati-se & $\mathbf{1 6 0}$ & 106 & 13,3 & 38,4 & 18,5 \\
Rio da Cidade & 120,1 & $\mathbf{1 8 5 , 8 *}$ & 141,3 & 33,3 & 23,2 \\
Pedro do Rio & 22,4 & 39,2 & $\mathbf{1 7 8 , 3 *}$ & 64,5 & 28,7 \\
Granja Gabi & 12 & 28 & 101,2 & $\mathbf{1 6 0 , 7} *$ & 31,4 \\
Fagundes & 14 & 29,9 & 55,6 & 37,1 & $\mathbf{1 1 5 , 6 *}$ \\
\hline
\end{tabular}

Para que os mapas de espacialização dos dados de precipitação demonstrassem a relação com a orografia (ou ausência dela), assim como a relação com os sistemas atmosféricos atuantes, de forma satisfatória, foram selecionadas outras sete estações que se encontravam a barlavento e sotavento do município, e que apresentassem dados de chuva nas datas selecionadas a partir das quatro estações principais. As estações complementares localizam-se nos municípios de Paraíba do Sul, Areal, Teresópolis, Sumidouro, Cachoeiras de Macacu, Guapimirim e Rio de Janeiro.

O critério de escolha para seleção das estações complementares se deu em função de auxiliar a distribuição das precipitações e na análise dos sistemas atmosféricos, uma vez que sistemas frontais podem provocar maiores volumes pluviométricos em áreas à barlavento da serra do mar e áreas próximas (como a estações do Rio de Janeiro por exemplo que, mesmo distante, pode auxiliar na análise do sistema atmosférico atuante) e, sistemas como a ZCAS podem provocar maiores volumes precipitados nas estações à sotavento (sentido LesteOeste) da Serra do Mar fluminense (estações de Paraíba do Sul e Sumidouro por exemplo). A figura 5 apresenta a distribuição das estações no mapa hipsométrico do estado do Rio de Janeiro 

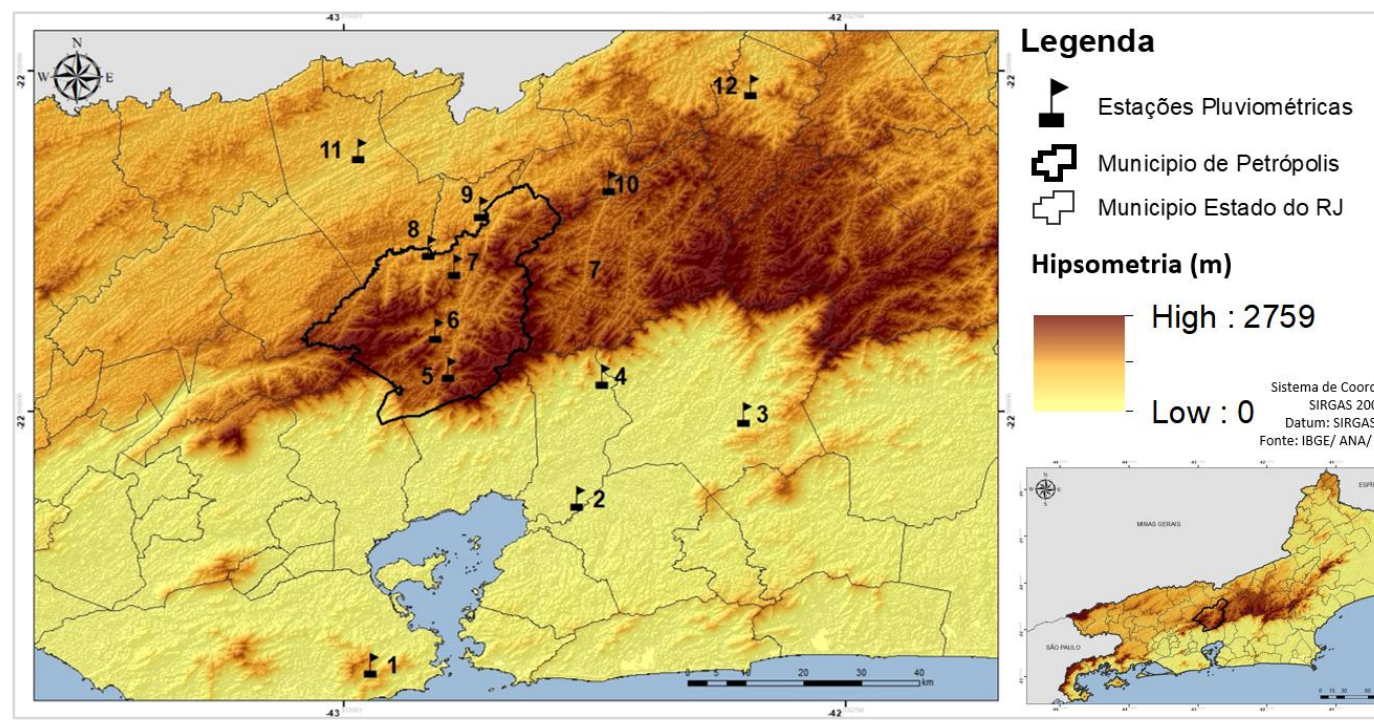

Hipsometria (m)

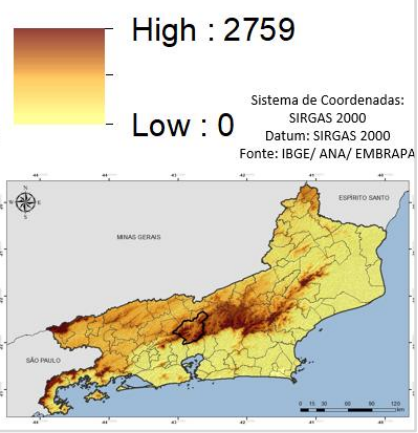

Figura 5 - Mapa de localização das estações sobre os dados hipsométricos do estado do Rio de Janeiro

Os dados de precipitação de cada uma das estações utilizadas para a espacialização dos eventos extremo-extremo podem ser aferidos na tabela 4.

Tabela 4 - Valores de precipitação $(\mathrm{mm})$ em cada uma das estações pluviométricas nas datas em que houve eventos extremos nas estações (Itamarati-se, Rio da Cidade, Pedro do Rio, Granjas Gabi e Fagundes). (*) Evento classificado como extremo-extremo. (**) zero correspondente à ausência de dado. (*) Estações complementares para espacialização dos dados

\section{ESTAÇÃO}

\section{Data do Evento Extremo}

$\begin{array}{cccccc} & 13 / 12 / 1981 & 24 / 12 / 1994 & 19 / 01 / 2003 & 24 / 12 / 2010 & 16 / 01 / 2016 \\ \text { Itamarati-se } & \mathbf{1 6 0 *} & 106 & 18,5 & 38,4 & 13,3 \\ \text { Rio da Cidade } & 120,1 & \mathbf{1 8 5 , 8 *} & 23,2 & 33,3 & 141,3 \\ \text { Pedro do Rio } & 22,4 & 39,2 & 28,7 & 64,5 & \mathbf{1 7 8 , 3} \\ \text { Granja Gabi } & 12 & 28 & 31,4 & \mathbf{1 6 0 , 7} * & 101,2 \\ \text { Fagundes } & 14 & 29,9 & \mathbf{1 1 5 , 6 *} & 37,1 & 55,6 \\ \text { Bomb. Imunana (*) } & 15,2 & 35 & 58,8 & 2,7 & 66,4 \\ \text { Japuíba (*) } & 0 & 56 & 19 & 9,3 & 56,3 \\ \text { Represa do Paraíso (*) } & 130 & 94,3 & 0 & 29,8 & 15,5 \\ \text { Paraíba do Sul (*) } & 0 & 50,2 & 17,5 & 40,1 & 128,2 \\ \text { Taboas (*) } & 22 & 19 & 10,3 & 74,3 & 56,1 \\ \text { Alto da Boa Vista (*) } & 31,2 & 19,7 & 7,4 & 13,6 & \mathbf{0}(* *) \\ \text { Fazenda Sobradinho (*) } & 9,4 & 0 & 15,9 & 80,4 & 89,7 \\ \text { Sumidouro (*) } & 0 & 81,6 & 25,1 & 0 & 69,3\end{array}$

Para a espacialização dos eventos escolhidos, o interpolador utilizado foi o IDW (Spatial Analyst > Interpolation > IDW, sendo executado pelo software ArcGis 10.2.2. É valido destacar que foram feitos testes com os métodos IDW e Kriging para ser escolhido aqueles que melhor respondia ao objetivo de demonstrar a espacialidade dos dados. 0 método kriging, em dois dos eventos 
estudados, não respondeu de forma satisfatória já que estimou um único valor para toda a área analisada, enquanto que as estações demonstravam variação expressiva entre os valores pluviométricos. Já o método IDW permitiu, para todos os eventos, a visualização da espacialidade dos dados de precipitação, sendo, portanto, o escolhido para aplicação nos dados e representação espacial dos mesmos.

Após a espacialização dos eventos extremo-extremo, juntamente com os mapas hipsométricos de Petrópolis e do estado do Rio de Janeiro, foi traçado um perfil topográfico, a partir de um transecto cortando a Serra do Mar e o município de Petrópolis, de forma que fosse possível demonstrar graficamente a diferença altimétrica das proximidades das estações pluviométricas, além de auxiliar na reflexão sobre a relação entre a espacialização dos eventos extremos de chuva com a orografia. Destaca-se que para a classificação das estações enquanto de baixa altitude, sobre a serra do mar e barlavento, considerou-se a hipsometria do local sobre o qual a estação está localizada. Assim, a estações Bomb.Imunana (3m), Japuba (25m) Represa do Paraíso (161) e Alto da Boa Vista $(347 \mathrm{~m})$ foram consideradas como estações de baixa altitude; as estações Itamarati-se $(793 \mathrm{~m})$, Rio da Cidade $(786 \mathrm{~m})$, Pedro do Rio $(729 \mathrm{~m})$, Fagundes (528m), foram classificadas como estações sobre a Serra do Mar (barlavento) e, as estações Fazenda Sobradinho $(754 \mathrm{~m})$, Paraíba do Sul (328m) e Sumidouro $(403 \mathrm{~m})$ foram classificadas como estações a sotavento. Concomitantemente ao mapeamento, foi efetuada a realização dos gráficos de precipitação em cada uma das estações para cada data analisada, assim como o gráfico de altitude de cada uma das sete estações utilizadas. Os mapas foram gerados de forma que fosse possível identificar a distribuição espacial das chuvas no município de Petrópolis quanto de suas imediações.

\subsection{LEVANTAMENTO E ANÁLISE DAS CARTAS SINÓTICAS}

Para análise dos sistemas atmosféricos atuantes sobre a área nos dias dos eventos escolhidos, foi feita a leituras das cartas sinóticas da Marinha do Brasil. As cartas sinóticas foram obtidas mediante solicitação ao órgão via email. A leitura das cartas foi feita a partir da convenção utilizada por Oliveira (2017) (figura 6C).

Para os eventos em que houve a disponibilidade, foi feita a leitura das imagens de satélite GOES12 como suporte a análise dos sistemas atmosféricos. As imagens foram obtidas através da plataforma online do CPTEC/INPE e, para a leitura, foi considerada a banda de nebulosidade sobre a área de estudos. A figura 6 A e B apresenta a área foco de análise nas leituras das cartas sinóticas e imagens GOES12.

É válido destacar que as vertentes da Serra do Mar podem alternar entre barlavento e sotavento a depender do sistema atmosférico atuante, nesse sentido, na leitura das cartas sinóticas e imagens de satélite considerou-se barlavento- vertente de frente para o oceano e sotavento: vertente de frente para o continente. 


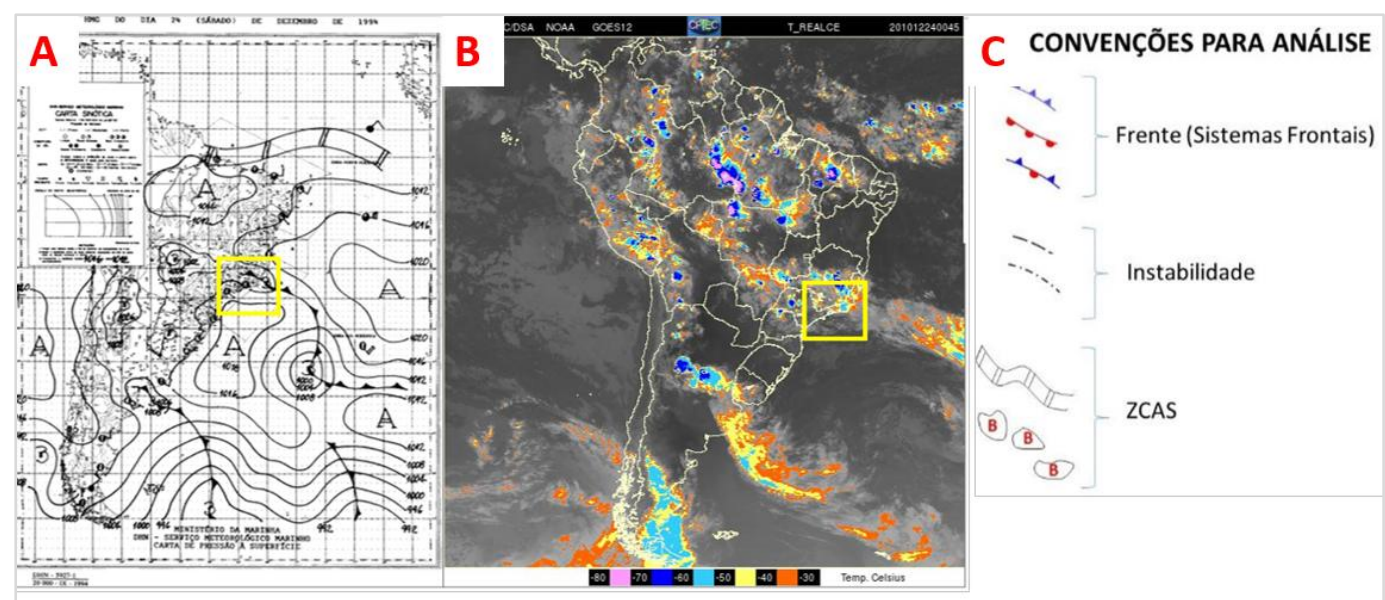

Figura 6 - A. carta sinótica do dia 24/12/1994 com a área de observação em foco. Fonte: Marinha do Brasil. B. Imagem de satélite GOES 12 com área de observação em foco. Fonte: CEPTEC/INPE. C. Convenções para análise e leitura das cartas sinóticas. Fonte: OLIVEIRA (2016)

\subsection{CORRELAÇÃO DOS DADOS PLUVIOMÉTRICOS COM AS ALTITUDES DAS ESTAÇÕES}

Para a verificação e análise da relação entre a orografia com os eventos extremo-extremos foi feita a média da altitude das estações de baixa altitude (Alto da Boa Vista, Bomb. Imunana, Japuba e Represa do Paraíso), estações sobre a Serra do Mar (Itamarati-se, Rio da Cidade, Pedro do Rio, Fagundes e Granja Gabi); estações a sotavento (sentido Leste-Oeste) (Fazenda Sobradinho, Paraíba do Sul e Sumidouro) e as médias dos volumes precipitados nessas estações nos eventos analisados.

Destaca-se que, ainda que a estação Alto da Boa Vista tenha altitude de $347 \mathrm{~m}$, foi considerada dentre as de baixa altitude por estar mais próxima ao litoral fluminense, ademais os mesmos cálculos foram feitos excluindo a estação o que não repercutiu em grandes mudanças nos coeficientes de correlação, uma vez que as demais estações de baixa altitudes apresentavam valores de 3 e 25 $\mathrm{m}$.

Com os valores médios foi feito os gráficos de correlação entre as duas variáveis para cada evento, assim como para a média do somatório dos totais precipitados. Além dos gráficos de correlação simples, foi aplicada aos dados a função "Correl" que tem por objetivo retorna o coeficiente de correlação entre dois conjuntos de dados (Equação 1). Ambas as aplicações foram executadas no software Excel.

Após a aplicação foram gerados os gráficos de correlação linear entre os volumes precipitados por evento em cada estação e as altitudes das estações, gráfico de linhas com os valores $\mathrm{R}^{2}$ (para indicar o evento que apresentou maior correlação entre os dados, e o gráfico de linha com os resultados obtidos através da aplicação da equação 1 indicando os eventos de maior/menor correlação entre as variáveis. 


$$
\operatorname{Correl}(X, Y)=\frac{\sum(x-\bar{x})(y-\bar{y})}{\sqrt{\sum(x-\bar{x})^{2}} \sum(y-\bar{y})^{2}}
$$

Onde $\bar{x} e \bar{y}$ são as médias altitude e média dos volumes precipitados nos eventos extremos

\section{RESULTADOS E DISCUSSÃO}

Ao avaliar os dados de precipitação para cada uma das sete estações utilizadas para espacialização dos eventos extremos de chuva, pode-se observar o maior volume pluviométrico (a partir da soma dos valores de chuva para todas as datas selecionadas) nas estações sobre a Serra do Mar (barlavento) localizadas nos municípios de Petrópolis e Areal (figura 7)

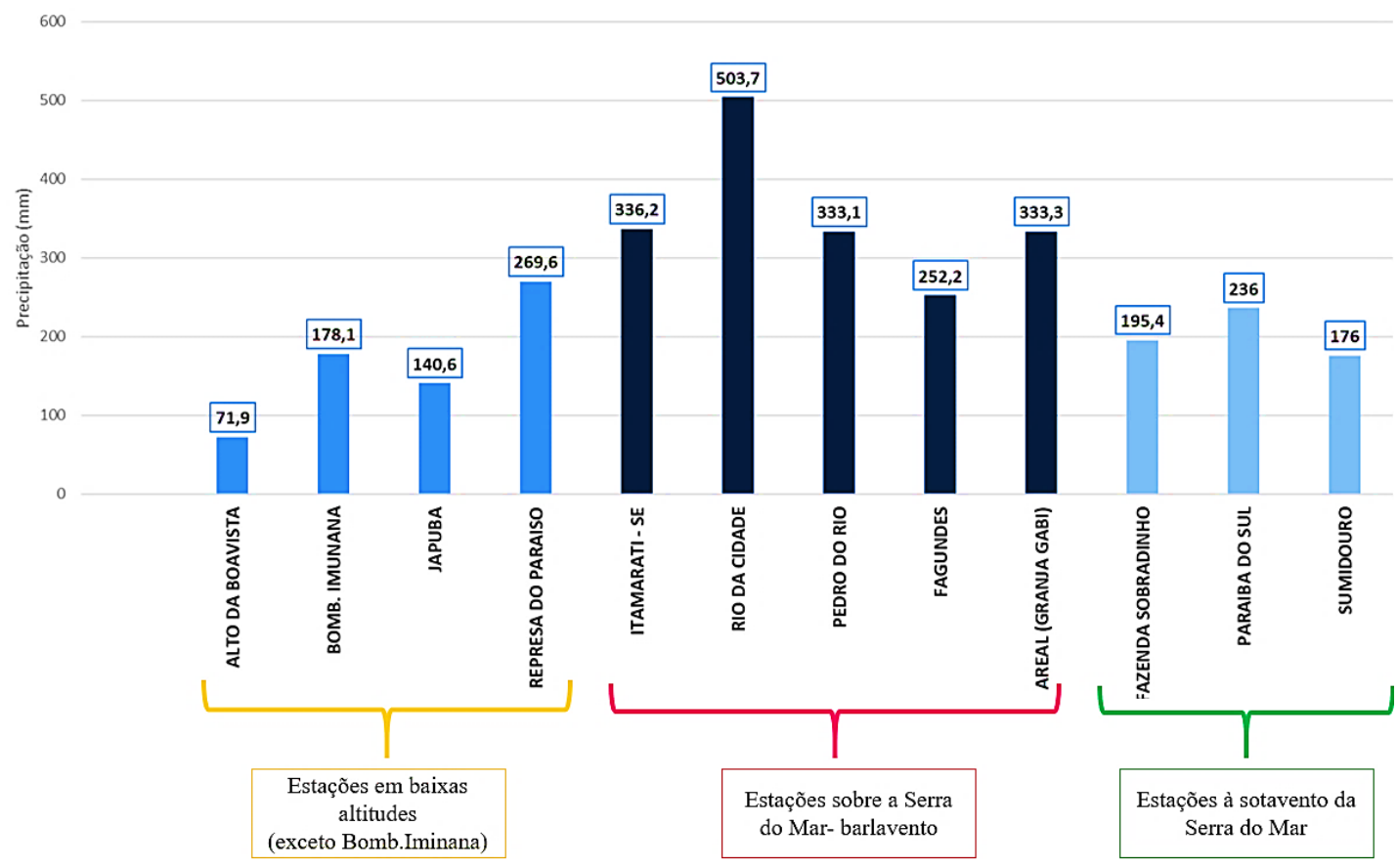

Figura 7 - Gráfico do total pluviométrico a partir do somatório dos eventos das datas analisadas para cada posto pluviométrico.

É possível observar que, ao considerar a soma dos eventos em cada estação, as áreas com maior volume pluviométrico recebido são as que correspondem as estações: Itamarati-se, Rio da Cidade, Pedro do Rio e Fagundes (localizadas no município de Petrópolis). As estações das baixas altitudes considerando a hipsometria onde as estações estão localizadas com altitude de $3 \mathrm{~m}$ a estação Bomb. Imunana altitude e $25 \mathrm{~m}$ a estação Japuba (exceto a estação Alto da Boavista que se localiza na $347 \mathrm{~m}$ de altitude, no Parque Nacional da Tijuca na cidade do Rio de Janeiro) apresentam os menores volumes de precipitação. Dentre as estações de baixa altitude a estação Represa do Paraíso no município de Guapimirim, por localizar-se bem próximo à Serra do Mar estando a $161 \mathrm{~m}$ de altitude, apresenta o maior volume de precipitação recebida no somatório dos eventos analisados totalizando 269,6 mm (para este primeiro conjunto de postos pluviométricos). A partir do gráfico apresentado é 
possível, ainda, observar que o volume de precipitação recebida no somatório dos eventos é menor nas estações a barlavento.

Ao analisar o perfil topográfico (figura 8) com o gráfico das altitudes das estações e os volumes de precipitação recebido pelos postos pluviométricos a partir do somatório dos eventos mais extremos para as estações nos municípios de Petrópolis e Areal (figura 9), observa-se que as áreas a barlavento receberam maiores volumes de chuva. Para verificar os padrões de relação da orografia com a distribuição das chuvas extremas e os sistemas atmosféricos atuantes foi analisado cada evento separadamente.

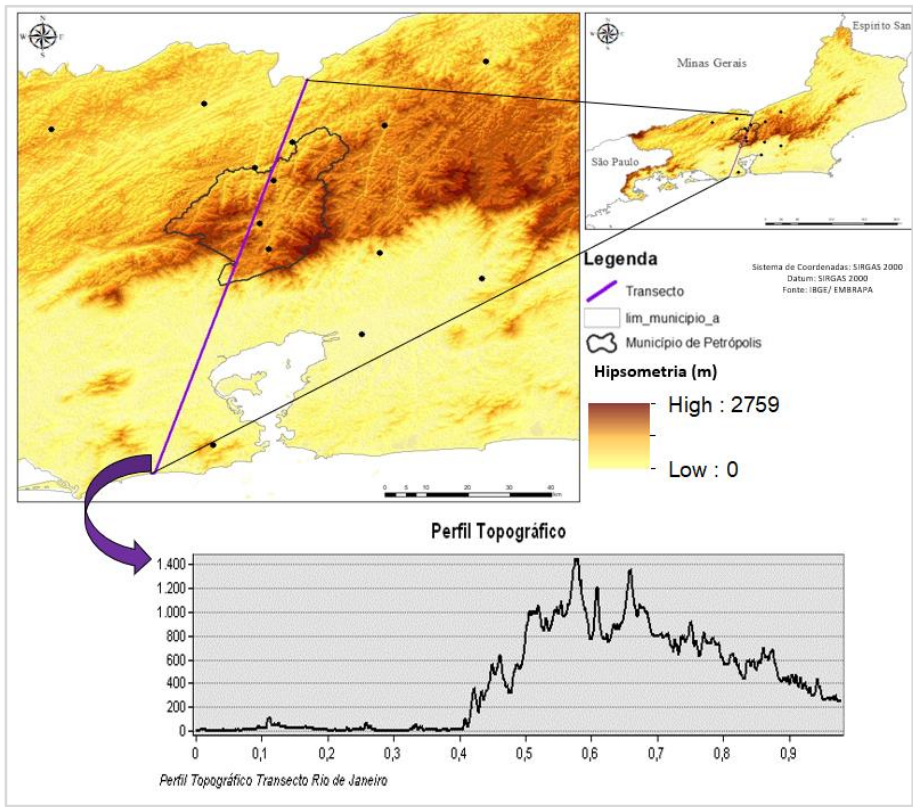

Figura 8 - Perfil topográfico interceptando a serra do mar no município de Petrópolis- RJ.

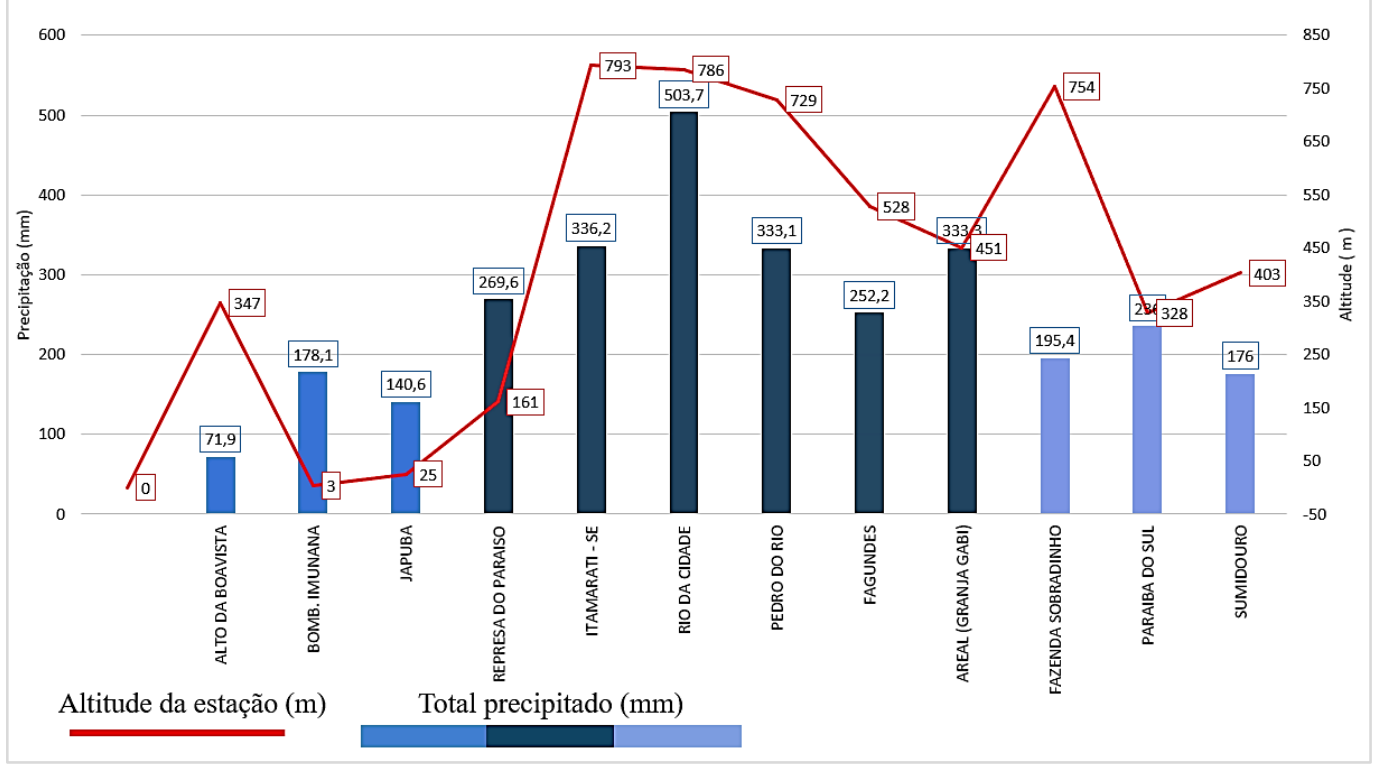

Figura 9 - Gráfico da Altitude dos postos pluviométricos com o volume total recebido de precipitação no somatório dos eventos analisados (eventos extremos-extremos). 


\subsection{O EVENTO DO 13-12-1981}

O evento extremo-extremo do dia 13/12/1981 foi identificado na estação Itamarati-se totalizando $160 \mathrm{~mm}$ em 24h. Ao analisar os mapas de espacialização da precipitação com os mapas hipsométricos do município de Petrópolis e do estado do Rio de Janeiro (figuras 10) é possível verificar que a precipitação ocorreu à barlavento da Serra do Mar (sentido Leste-Oeste) com os maiores valores de precipitação no sul e sudeste do município. Destaca-se ainda, que a precipitação se distribuiu no fundo de vale do município tendo seu volume diminuído nas áreas de maior elevação no interior do município (oeste) com altitude variando entre $1166 \mathrm{~m}-1736 \mathrm{~m}$. verifica-se, na parte superior da figura 10 que os maiores volumes concentram-se na vertente leste da Serra do Mar.
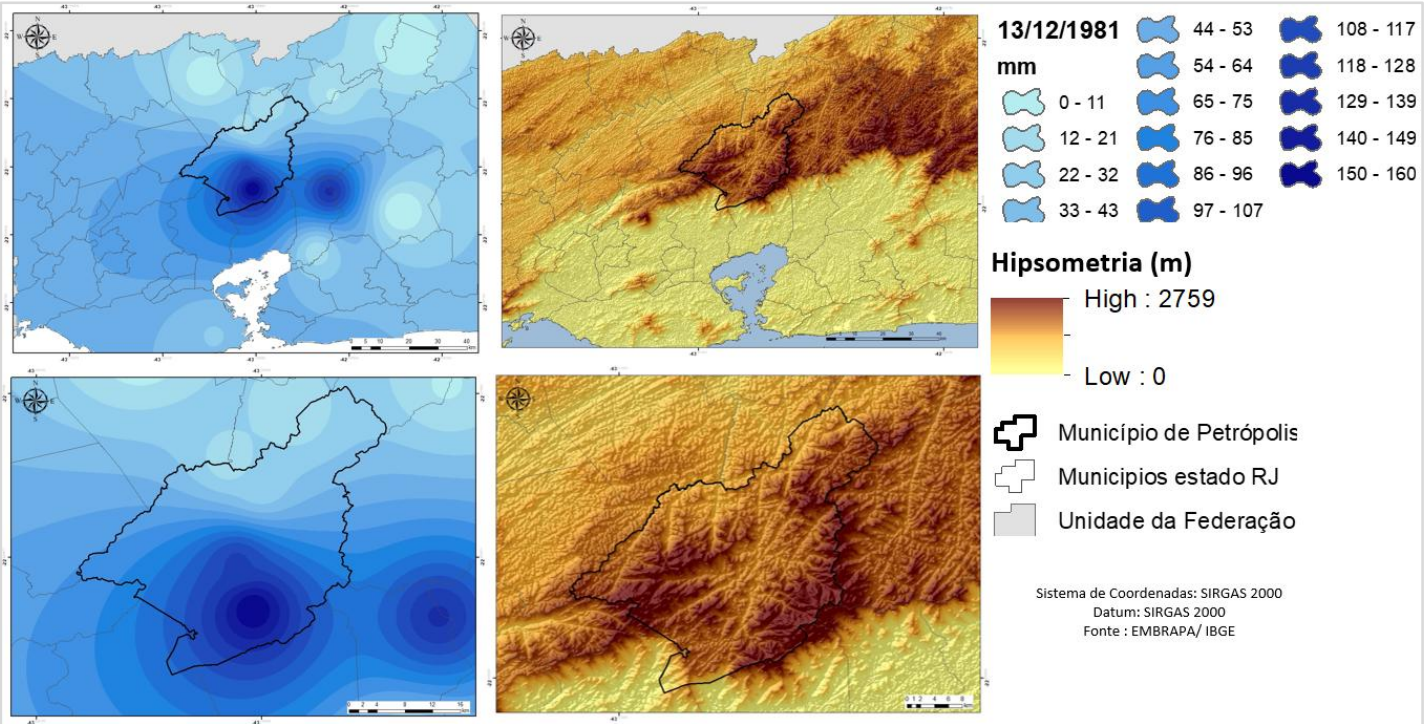

Município de Petrópolis

Municipios estado RJ

Unidade da Federação

Sistema de Coordenadas: SIRGAS 2000
Datum: SIRGAS 2000 Fonte : EMBRAPA/ IBGE

Figura 10 - mapa de espacialização das chuvas de 13/12/1981 para o município de Petrópolis e arredores; mapa hipsométrico do município de Petrópolis-RJ e arredores.

A partir da leitura da carta sinótica (Figura 11), verificou-se a atuação de um sistema frontal e, em sua retaguarda uma massa de ar polar atlântica $(\mathrm{mPa})$. "No verão o trajeto preferencial [da $\mathrm{mPa}$ ] é pelo litoral e interior do Atlântico" (BORSATO,2016 p.55). Esse sistema frontal atuante causa instabilidade atmosférica o que pode ter provocado os elevados volumes pluviométricos a barlavento da Serra do Mar, fazendo com que o sul e o sudeste do município de Petrópolis recebessem o maior volume de chuva. A partir do gráfico de volume de precipitação nas estações com os dois perfis topográficos é viável inferir que esse sistema frontal atuante provocou chuva nas altitudes mais baixas (município do Rio de Janeiro e Guapimirim) com 31,2 e 15,2 mm, respectivamente, e o evento extremo-extremo de $160 \mathrm{~mm}$ no município de Petrópolis, uma vez que, na entrada do sistema frontal, a umidade vinda do oceano, ao encontrar com a serra do mar provocou significativo evento de chuva no município de Petrópolis. 

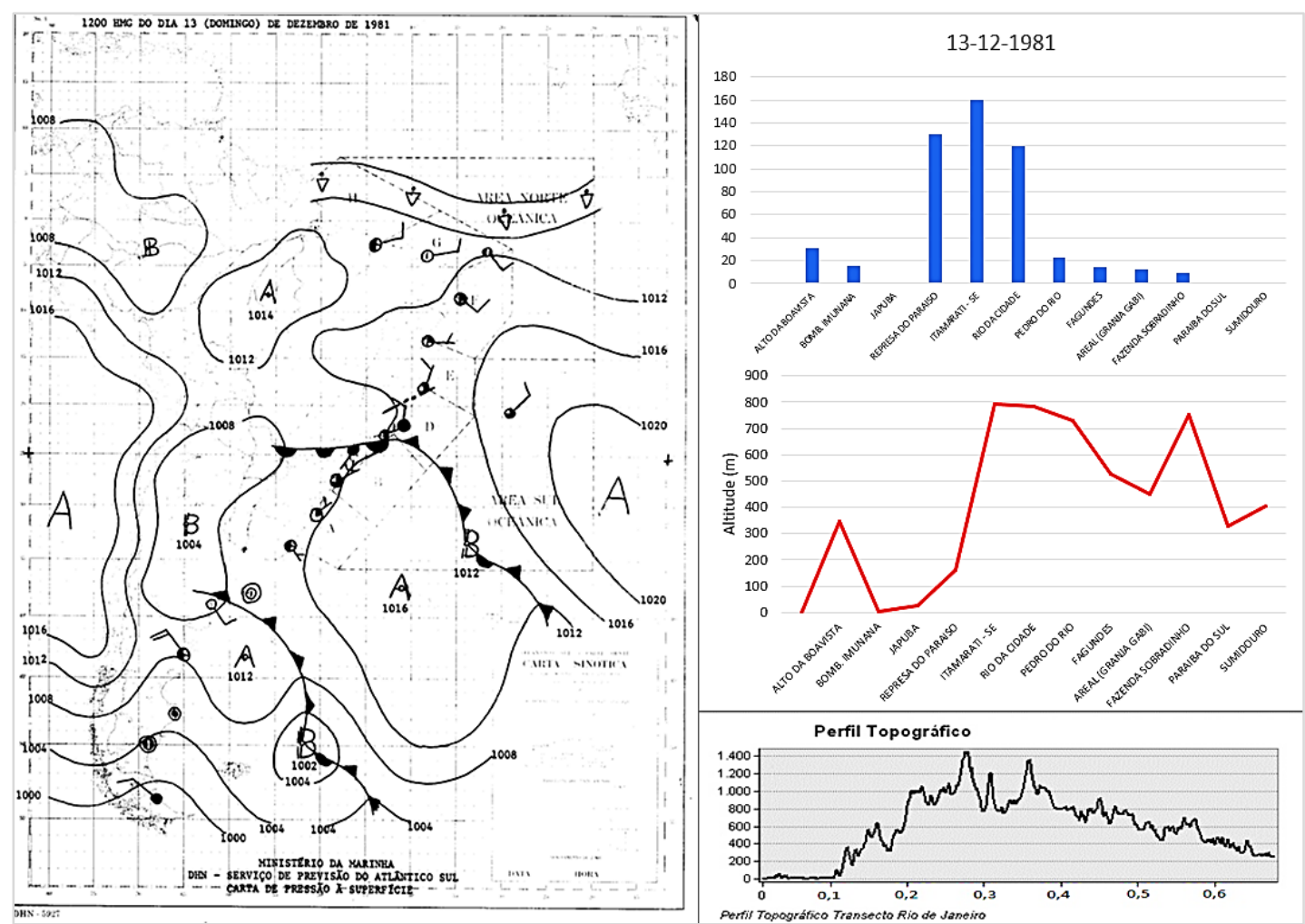

Figura 11 - Carta sinótica do dia 13-12-1981 com os respectivos gráficos de volume total de precipitação $(\mathrm{mm})$ nas sete estações utilizadas, gráfico de altitude das estações e o perfil topográfico interceptando a serra do mar e o município de Petrópolis- RJ.

\subsection{O EVENTO DE 24-12-1994}

As figuras 12 apresenta a espacialização dos dados de chuva para o evento de 24-12-1994 (considerado extremo a partir da estação Rio da Cidade com 185,8 mm em 24h) e a hipsometria do município de Petrópolis. Observa-se que os maiores volumes de chuva foram identificados na área central do município correspondendo ao fundo de vale. Os menos valores estão ao norte do município o que indica que o sistema atmosférico é proveniente do sudeste (sistemas frontais vindos do oceano). A partir da observação da figura 13 verifica-se, assim como no evento anteriormente analisado a passagem de um sistema frontal e a instalação da $\mathrm{mPa}$. Vale ressaltar que, em ambos os casos as $\mathrm{mPa}$ deslocam-se principalmente sobre o oceano e, o sistema frontal atuante adentra mais significativamente no continente se comparado à massa polar. Isso, porque uma das características da mPa é seu deslocamento, no verão, se dar, majoritariamente sob o oceano, enquanto que no inverno além de serem mais intensas avançam com mais frequência pelo interior do continente (BORSATO, 2016 p.101). 

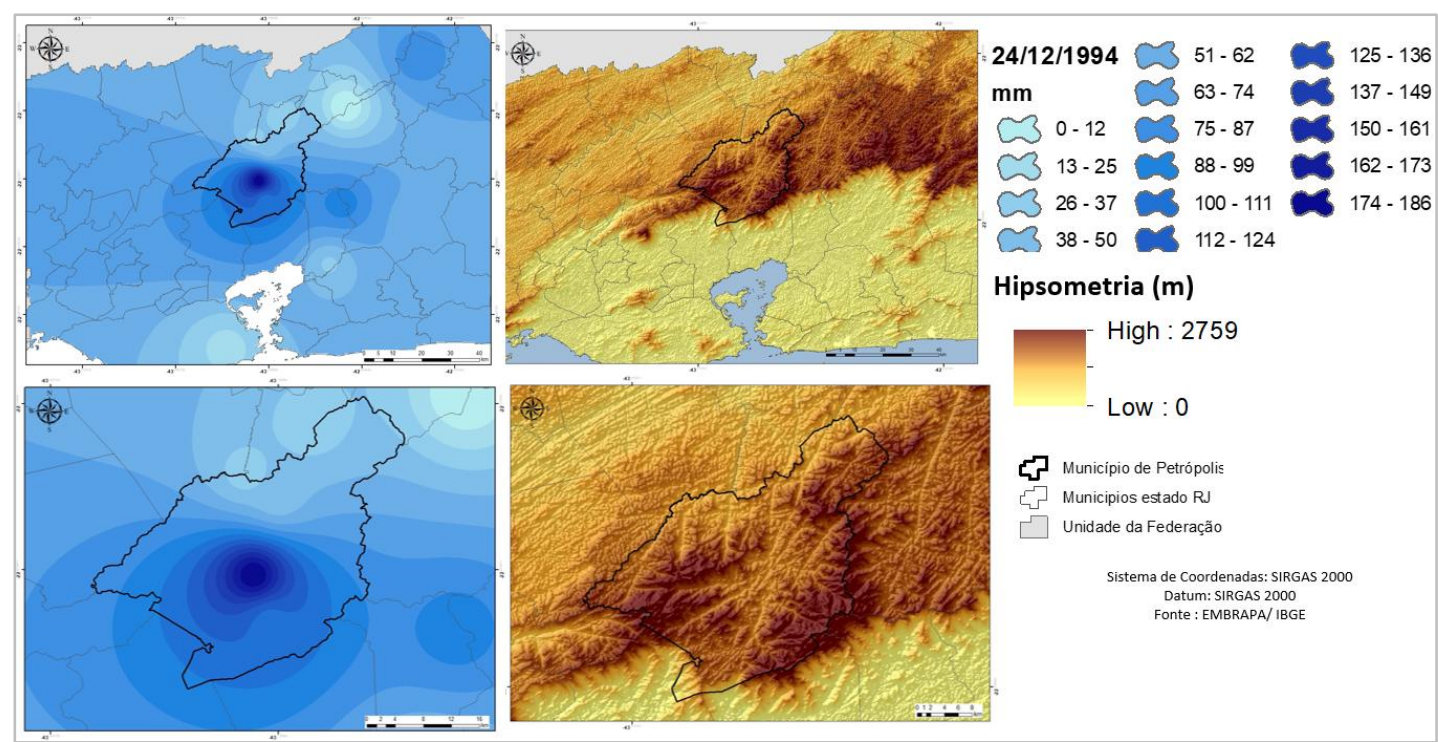

Hipsometria (m)

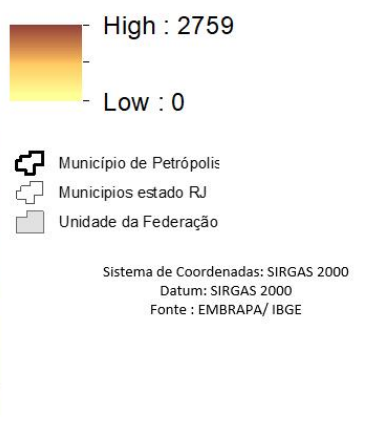

Figura 12 - mapa de espacialização das chuvas de 24/12/1994 para o município de Petrópolis e arredores; mapa hipsométrico do município de Petrópolis-RJ e arredores.


Figura 13 - Carta sinótica do dia 24-12-1994 com os respectivos gráficos de volume total de precipitação $(\mathrm{mm})$ nas sete estações utilizadas, gráfico de altitude das estações e o perfil topográfico interceptando a serra do mar e o município de Petrópolis- RJ.

Considerando as imagens apresentadas, observa-se que a passagem do sistema frontal provocou chuva em todas estações analisadas com os maiores volumes nas estações a barlavento da serra do mar no município de Petrópolis. 


\subsection{O EVENTO DE 19-01-2003}

O evento de 19-01-2003 foi registrado na estação Fagundes na divisa entre os municípios de Petrópolis e Areal, sendo esse evento de 115,6 mm. A partir da espacialização dos volumes pluviométricos referentes a data de 19 de janeiro de 2003 que os maiores volumes de precipitação a partir do mapa localizam-se a noroeste do município (figura 14). É possível ainda, na comparação dos mapas de espacialização e hipsometria que a precipitação é interceptada pela própria elevação à W-SW do município tornando-se uma barreira e influenciando na espacialização da precipitação. Ao se observar as cartas sinóticas da data deste evento verifica-se que a área de estudos se encontra nas bordas de duas células uma de baixa e outra de alta pressão. Observa-se ainda a passagem de uma frente fria, carregando umidade do oceano para o continente gerando instabilidade atmosférica. O relatório da Marinha do Brasil para data deste evento há a dissipação de uma frente fria nas coordenadas 45S027W, 39S030W E 33S035W e uma frente quase estacionária sobre Vitória/ES (figura 15). A passagem desse sistema frontal provocou as pancadas de chuva apresentadas no relatório da Marinha do Brasil para a data apresentada.

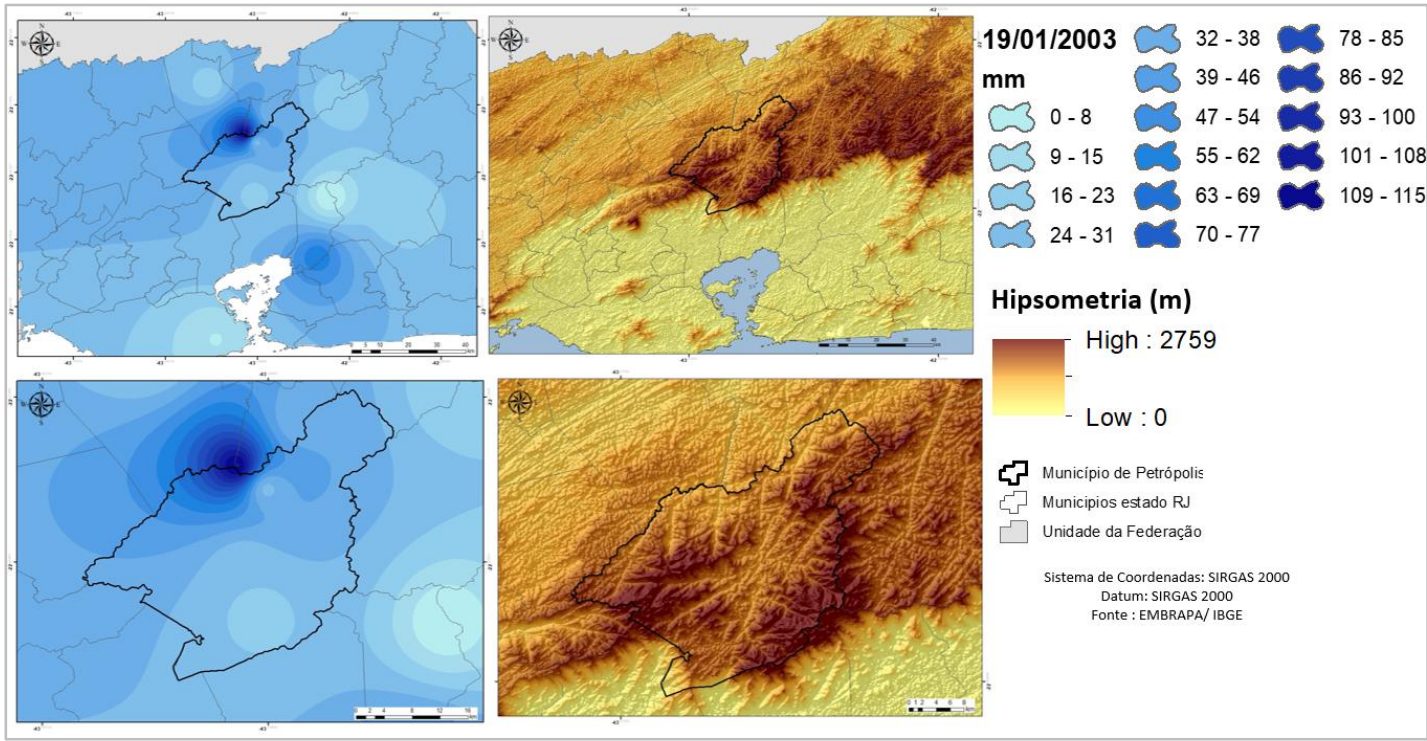

Figura 14 - mapa de espacialização das chuvas de 19/01/2003 para o município de Petrópolis e arredores; mapa hipsométrico do município de Petrópolis-RJ e arredores.

A partir do gráfico de distribuição do volume de precipitação nas estações analisadas observa-se que o evento extremo do dia 19-01-2003 refere-se a uma pancada de chuva nas áreas próximas a estação Fagundes (limite dos municípios Petrópolis e Areal). O padrão de elevado volume de precipitação não é identificado nas demais estações sendo, que os quatro principais postos pluviométricos analisados (Itamarati-se, Rio da Cidade, Pedro do Rio e Granja Gabi) registraram, respectivamente, os seguintes volumes de precipitação: $18,5 \mathrm{~mm}, 23,2 \mathrm{~mm}, 28,7 \mathrm{~mm}, 31,4 \mathrm{~mm}$. 


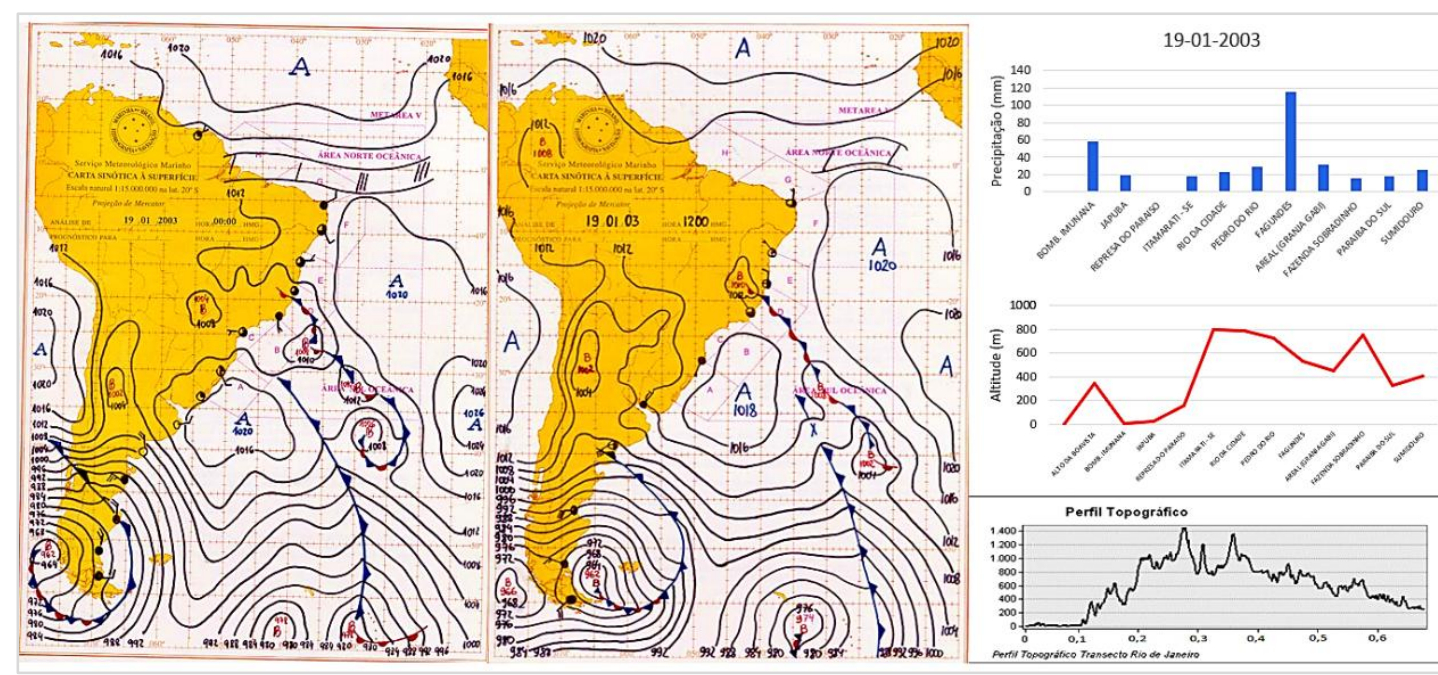

Figura 15 - Cartas sinóticas (00 e 12:00) do dia 19-01-2003 com os respectivos gráficos de volume total de precipitação $(\mathrm{mm})$ nas sete estações utilizadas, gráfico de altitude das estações e o perfil topográfico interceptando a serra do mar e o município de PetrópolisRJ.

\subsection{O EVENTO DO 24-12-2010}

O evento de 24-12-2010 foi registrado na estação Granja Gabi com volume precipitado de $160,7 \mathrm{~mm}$. A partir do mapa de espacialização e do gráfico de volume precipitado por estação (figuras 16 e 17) é possível observar que o vetor de direção das precipitações é de NW-SE sendo verificados os maiores valores de precipitação a sotavento (considerando barlavento a vertente da serra do mar de frente para o oceano). Ao observar a imagem de satélite Goes 16 identifica-se uma banda de umidade que segue o sentido NWSE se situando, portanto, sobre a área de estudo. A partir das cartas sinóticas vê-se uma linha de instabilidade passando sob a área de estudo que é formada a partir do encontro de duas massas de ar. Mediante a análise sinótica conferese o contato de duas células (uma de baixa pressão com seu centro bem próximo a área de estudos com contato com as bordas da célula de alta pressão localizada próximo aos sul sobre o Oceano Atlântico).

Em termos da espacialização dos dados de precipitação, é visível que os maiores volumes se concentram ao norte do município com persistência de precipitação nos demais postos pluviométricos, demonstrando a passagem da linha de instabilidade. Ao avaliar a passagem da linha de instabilidade comparando os dados pluviométricos aos mapas hipsométricos (do município e do estado), pode-se considerar que a linha de instabilidade provocou maiores volumes de precipitação a sotavento (que, por sua vez encontra-se mais próximo ao centro de baixa pressão) e menores valores a barlavento, demonstrando que a orografia influenciou na potencialização da precipitação sob as áreas próximas ao posto pluviométrico. 


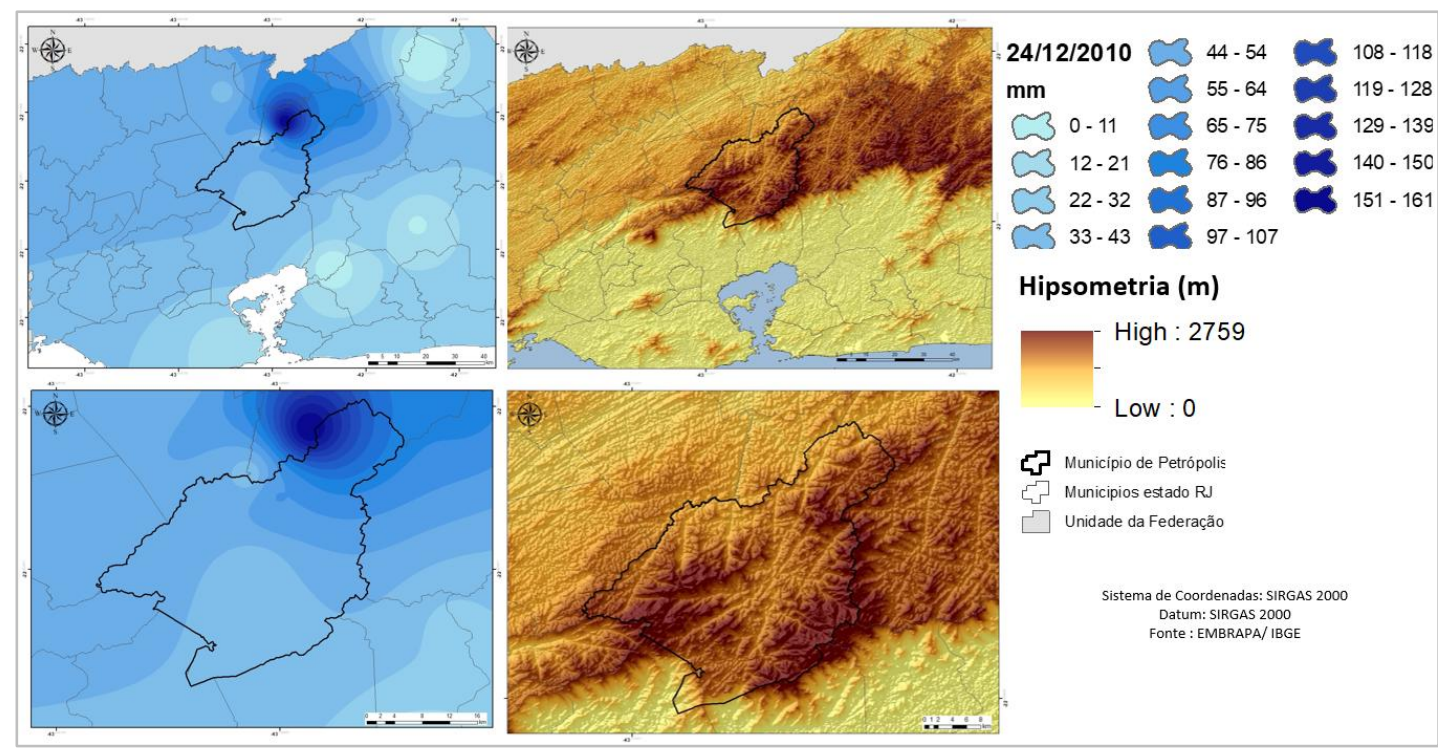

Figura 16 - Mapa de espacilização dos dados de chuva para o dia 24/12/2010 para o município de Petrópolis e arredores e mapa hispsométrico do municipio de Petrópolis- RJ e arredores.

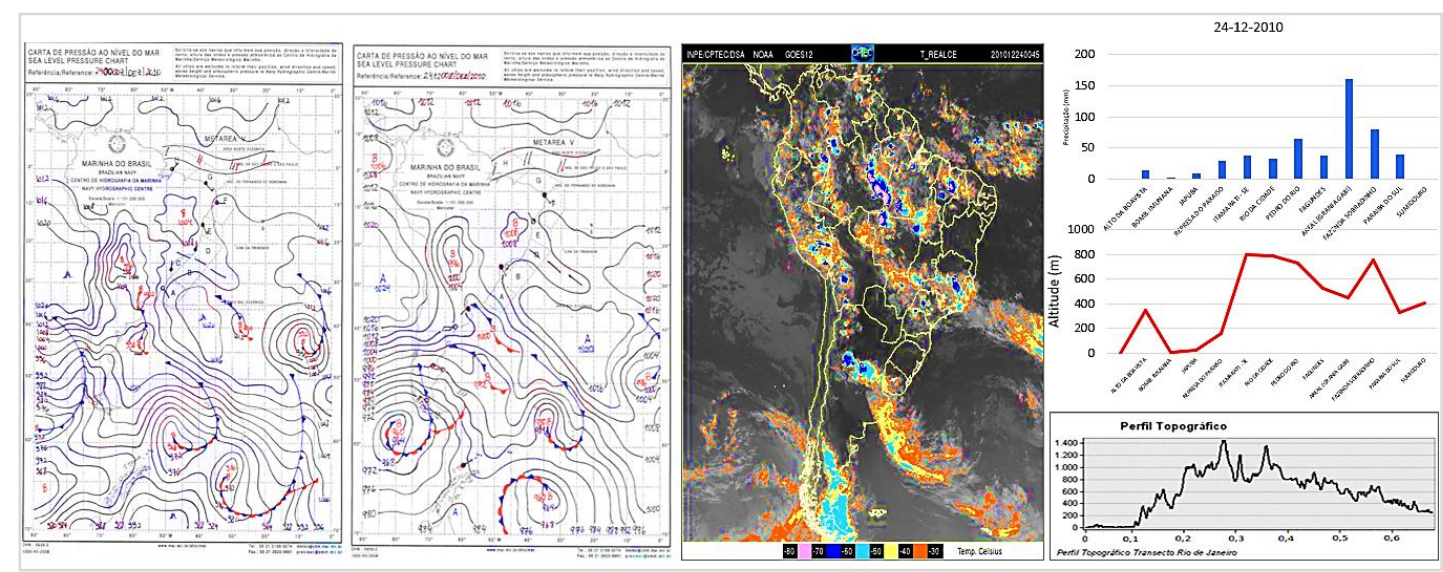

Figura 17 - Carta sinótica do dia 24-12-2010; imagem de satélite Goes 16; com os respectivos gráficos de volume total de precipitação $(\mathrm{mm})$ nas sete estações utilizadas, gráfico de altitude das estações e o perfil topográfico interceptando a serra do mar e o município de Petrópolis- RJ.

\subsection{O EVENTO DE 16-01-2016}

O evento extremo de 16-01-2016 corresponde a estação Pedro do Rio totalizando o volume de $178,3 \mathrm{~mm}$ precipitados. As figuras 18 e 19 apresenta a espacialização dos dados de chuva estando os maiores volumes no fundo de vale e no centro do município. A partir da análise concomitante do mapa de espacilização com as cartas sinóticas com o gráfico de volume precipitado em cada posto analisado, observa-se a ação de dois sistemas atmosféricos atuantes. O primeiro refere-se a Zona de Convergencia do Atlântico Sul -ZCAS (banda de nebulosidade no sentido NW-SE) e a entrada de um sistema frontal vindo do oceano. A ação da ZCAS provocou elevados volumes pluviométricos nas estações a sotavendo enquanto que, apesar de provocar chuva nas estações a barlavento, o volume é consideravelmente menor, indicando que a orografia 
exece influencia na distribuição espacial do evento. Mesmo com ação de dois sistemas atmosféricos atuantes sobre os postos pluviométricos localizados nas baixas altitudes, os maiores volumes encontram-se nas estações sobre a serra do mar. Destaca-se, dessa forma, a alternancia entre as vertentes a sotavento e barlavento a depender do sistema atomsférico que provoca chuvas sob a região. Para o evento de 16-01-2016 as estações localizadas nas maiores altitudes apresentaram, também, os maiores volumes pluviométricos.
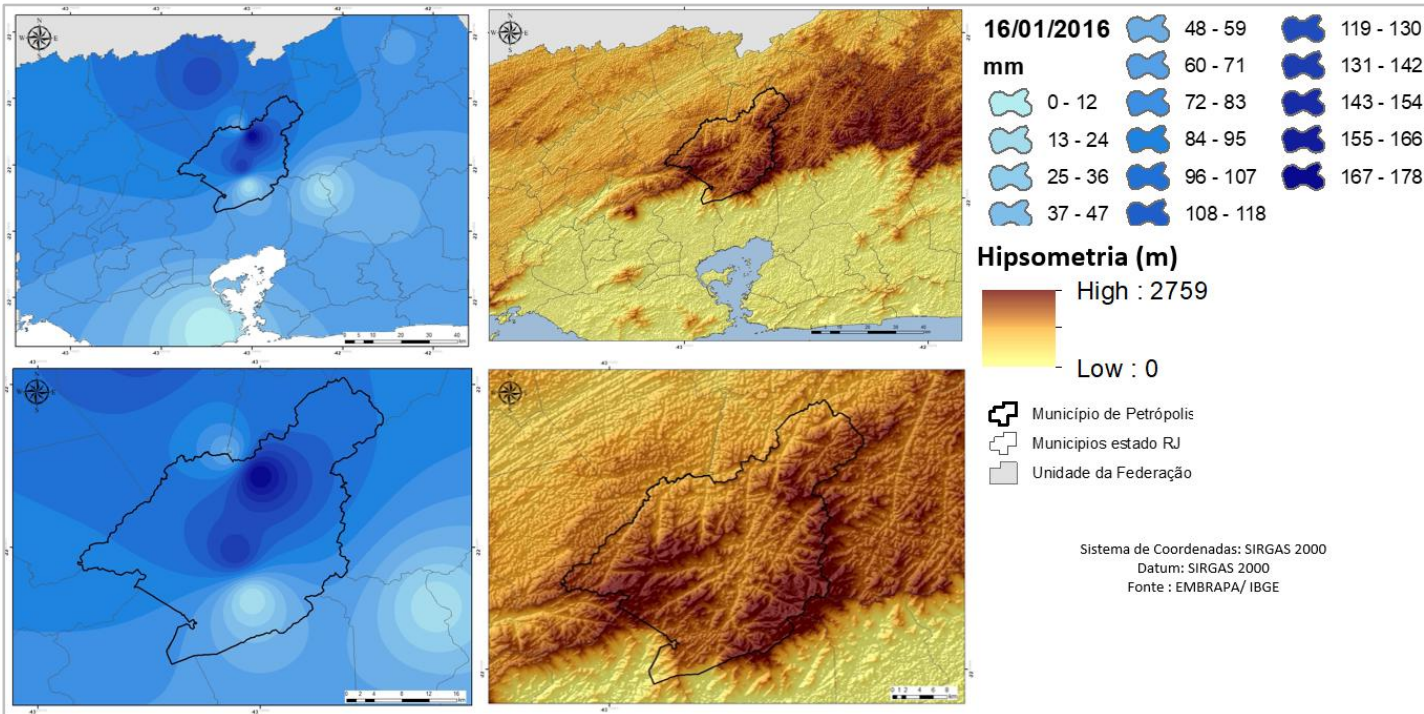

Hipsometria (m)
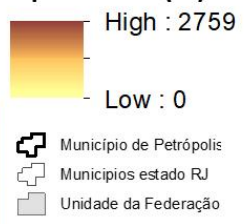

Sistema de Coordenadas: SIRGAS 2000 Datum: SIRGAS 2000

Figura 18 - Mapa de espacilização dos dados de chuva para o dia 16-01-2016 e arredores; mapa hispsométrico do municipio de Petrópolis- RJ e arredores.

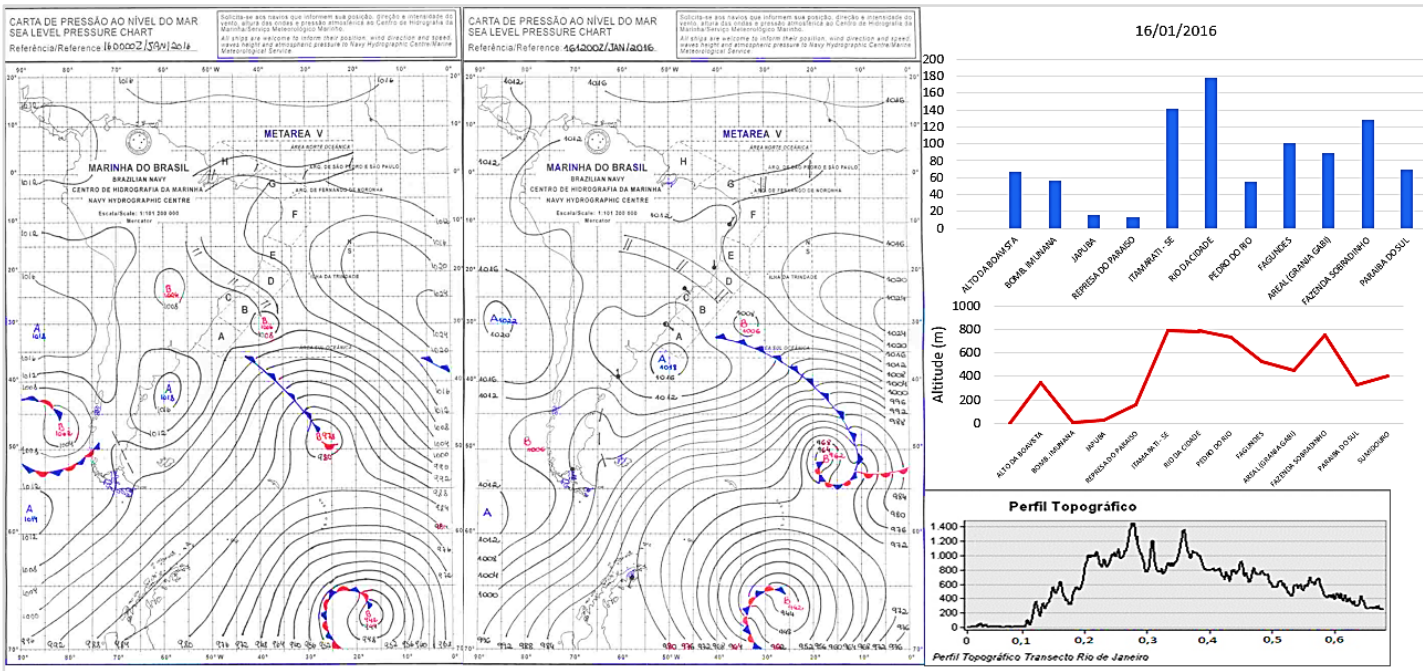

Figura 19 - Cartas sinóticas (00 e 12:00) do dia 19-01-2003 com os respectivos gráficos de volume total de precipitação $(\mathrm{mm})$ nas sete estações utilizadas, gráfico de altitude das estações e o perfil topográfico interceptando a serra do mar e o município de PetrópolisRJ.

\subsection{ANÁLISE DA CORRELAÇÃO}

A figura 20 e 21 apresenta os dados de correlação linear entre as médias das atitudes das estações de baixa altitude (Alto da Boa Vista, Bomb. Imunana, 
Japuba e Represa do Paraíso), estações sobre a Serra do Mar (Itamarati-se, Rio da Cidade, Pedro do Rio, Fagundes e Granja Gabi); estações a sotavento (sentido Leste-Oeste) (Fazenda Sobradinho, Paraíba do Sul e Sumidouro) com as médias dos volumes precipitados nessas estações nos eventos analisados.

Segundo os dados médios, os eventos 24/12/2010, 16/01/2016 e a média do somatório de precipitação apresentou uma correlação significativa com $R^{2}$ entre 0,81 e 0,99. O evento de menor correlação foi 13/12/1981 com $R^{2}$ de 0,084 , todos os demais eventos apresentaram correlação considerável, uma vez que apresentaram $R^{2}>0,5$. Destaca-se que, quanto mais próximo a 1,0 for $R^{2}$, maior é a correlação entre as variáveis analisadas. Dessa forma, considerou-se significativo o coeficiente de correlação $>0,7$; relevante os $\geq 0,5$ e sem correspondência os $<0,5$. Assim, apresentou correlação significativa os eventos de 24/12/2012, 16/01/2003 e a média da soma; relevante os eventos de 24/12/1994 e 19/01/2003 e sem correspondência o evento de 13/12/1981.
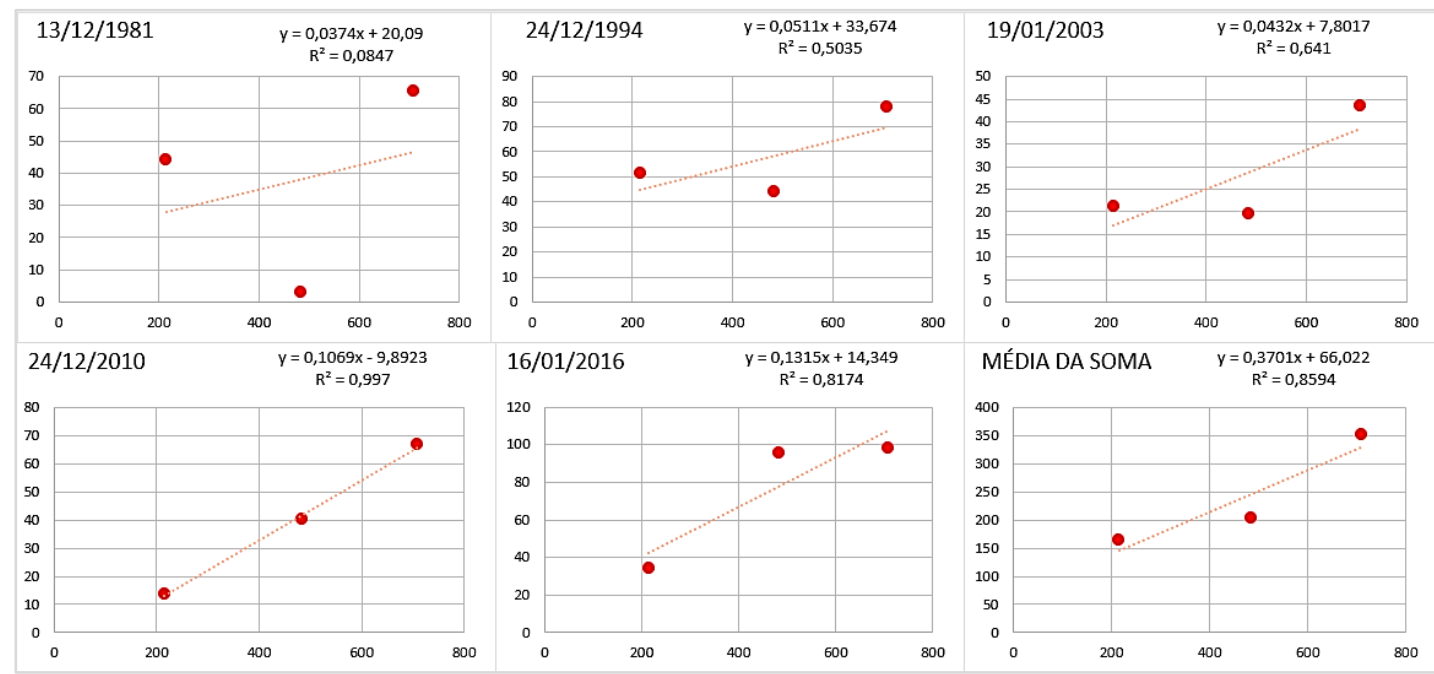

Figura 20 - Gráficos de correlação linear entre as médias das altitudes nas estações de baixa altitude, sobre a Serra do Mar e a sotavento da Serra do Mar; com os respectivos valores médios de volume precipitado.

Segundo os dados médios, o evento de maior correlação entre as variáveis analisadas foi o de 24/12/2010, assim como nas análises individuais. É possível ainda considerar que quatro dos cinco eventos analisados correspondem a um coeficiente de correção $>0,5$ indicando que há correspondência entre áreas de maior média de altitude com a média dos maiores volumes de precipitação. É pertinente salientar que a opção por avaliar as médias das altitudes e das precipitações se deu em função de se entender que os dados médios apresentam uma condição tanto do ponto aferido quanto das imediações, já que estabelece uma média entre as informações tanto de altitude quanto precipitadas nas áreas correspondentes à baixa altitude, barlavento e sotavento (sentido Leste-Oeste). 

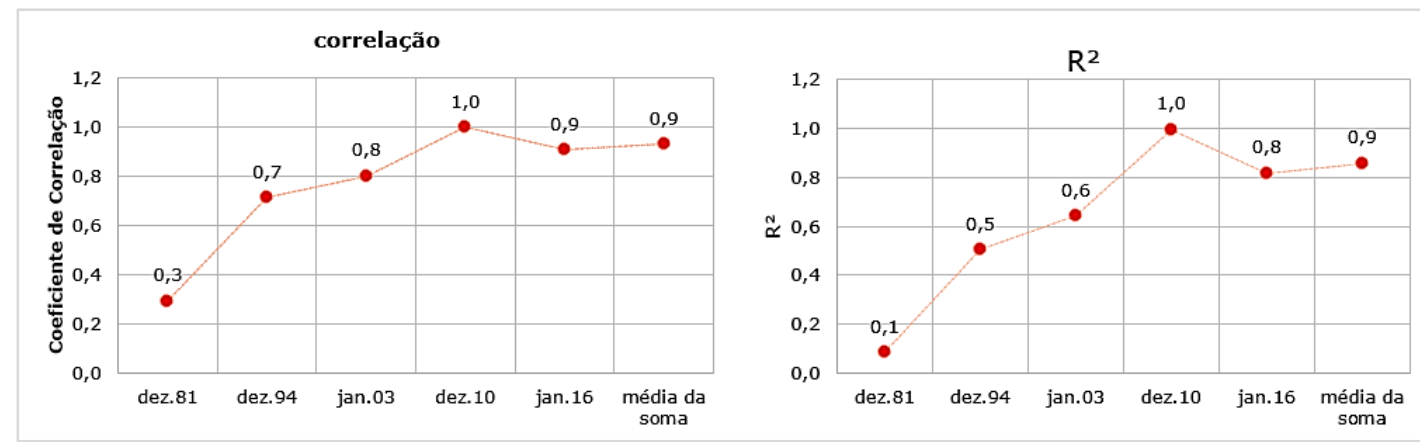

Figura 21 - Gráficos de correlação linear entre as médias das altitudes nas estações de baixa altitude, sobre a Serra do Mar e a sotavento da Serra do Mar; com os respectivos valores médios de volume precipitado.

\section{CONCLUSÃO}

A partir do exposto observa-se que todos os eventos mais extremos identificados nas quatro principais estações analisadas ocorreram no verão, mais precisamente nos meses de dezembro e janeiro. Os principais sistemas atmosféricos atuantes foram os sistemas frontais, a MPA e a ZCAS convergindo umidade para área de estudo e provocando os elevados volumes pluviométricos.

Verificou-se que quando houve atuação dos sistemas frontais e chegada da MPA os maiores volumes pluviométricos foram nas estações a barlavento da serra do mar enquanto que, quando houve atuação da linha de umidade proveniente do interior do continente, os maiores volumes precipitados se deram nas estações a sotavento (alterando, portanto, as condições de sotavento e barlavento).

Ao analisar a distribuição das chuvas espacialmente com os valores altimétricos das estações, assim como o perfil topográfico traçado, pôde-se observar que a topografia interfere significativamente na distribuição das chuvas, tanto em ralação a distribuição no interior do município (como o caso dos eventos de 13-12-1981; 24-12-1994; 19-01-2003 e 16-01-2016) como considerando a serra do mar a partir do mapa hipsométrico do estado do Rio de Janeiro bem evidenciado no evento 13-12-1981.

Nas análises de correlação entre as altitudes médias e os volumes médios precipitados nos eventos, observou-se que $80 \%$ dos eventos tiveram $\mathrm{R}^{2}$ $>0,5$ e apenas 1 evento (20\%) apresentou $\mathrm{R}^{2}<0,5.20 \%$ dos eventos apresentaram correlação significativa (2 eventos) e $20 \%$ foram considerados relevantes nessa análise (2 eventos). É possível verificar que, tanto os mapas quanto as correlações indicaram que a orografia influencia na distribuição dos eventos extremo-extremos. Nesse sentido, cidades edificadas sobre áreas de topografia elevada, merecem atenção em termos dos estudos dos eventos extremos, uma vez que, os próprios elementos naturais podem potencializar esses eventos, além da alteração do homem no espaço que, potencializa o impacto.

A técnica empregada de determinação e classificação dos eventos extremos respondeu bem ao objetivo do trabalho, além de selecionar os eventos mais extremos da série histórica e classifica-los em termos de suas 
intensidades. O uso da técnica permite estudos dos eventos que mais fogem da normalidade/ habitualidade dos dados, direcionado o olhar às excepcionalidades presente em um conjunto de dados/ em uma dada área de estudos.

O mapeamento das distribuições da precipitação e sua comparação com os mapas hipsométricos do munício de Petrópolis e suas imediações, permitiu visualizar que a orografia exerce um importante papel da distribuição da precipitação. O presente trabalho apresentou que, para o município de Petrópolis e arredores a orografia exerce papel relevante na distribuição dos eventos mais extremos da série, no entanto, é necessário, ainda avaliar se esse mesmo padrão é identificado para as demais classes de intensidade dos eventos extremos e, para os eventos habituais da série histórica, uma questão a ser estudada futuramente. Ademais, além dessa relação, é interessante, ainda, elucubrar sobre os sistemas atmosféricos e quais, que em atuação, apresentam maior correlação com a orografia local em termos do volume de precipitação.

\section{AGRADECIMENTOS}

Agradecimentos à CAPES pela concessão de bolsa de mestrado a primeira autora

\section{REFERÊNCIAS BIBLIOGRÁFICAS}

ARMOND, N.; SANT'ANNA NETO, J. L.S. Entre eventos e Episódios: ritmo climático e excepcionalidades para uma abordagem geográfica do clima no município do Rio de Janeiro. Revista Brasileira de Climatologia. Ano 13 - Vol. 20 - JAN/JUL 2017

AYOADE, J. O. Introdução à Climatologia para os Trópicos. $4^{a}$ ed. Rio de Janeiro; Bertrand Brasil, 1996. 332 p.

BORSATO, V. A dinâmica climática do Brasil e massas de ares. $1^{a}$ ed.- Curitiba, PR. CRV, 2016 184p.

BOUSQUET, O.; SMULL, B. F. Observation and impacts of upstream blocking during a widespread orographic precipitation event. Q. J. R. Meteorol. Soc. (2003), 129, pp. 391-409

CÂNDIDO, N. H.; NUNES, L. H. Influência da orografia na precipitação da área entre o vale do Rio Tietê e a Serra da Mantiqueira. GEOUSP - Espaço e Tempo, São Paulo, No 24, pp. 08 - 27, 2008.

CARVALHOS, L. M. V.; JONES, C.; LIEBMANN,B. Extreme Precipitation Events in Southeastern South America and Large-Scale Convective Patterns in the South Atlantic Convergence Zone. Jornal of climate, 2002 American Meteorological Society, v.15

CENTRO UNIVERSITÁRIO DE ESTUDOS E PESQUISA SOBRE DESASTRES NATURAIS. Atlas Brasileiro de desastres naturais 1991 a 2012. 2. ed. rev. ampla. - Florianópolis: CEPED UFSC, 2013. 120 p.: il. color.; 22 cm. Volume Rio de Janeiro

COELHO, M. C. N. Impactos ambientais em áreas urbanas- Teoria, Conceitos e Métodos de Pesquisa. In: GUERRA, A. J. T.; CUNHA, S. B. (Org.) Impactos 
ambientais urbanos no Brasil. 11aed.- Rio de Janeiro, Bertrand Brasil, 2014. $418 p$.

FORGINARI, F. R.; VENDRUSCULO, D. S.; RIZZI, E.S.; Análise de chuvas orográficas no centro do estado do Rio Grande do Sul. Ciência e Natura, v. 36 n. 2 mais-ago. 2014, p. $193-200$

FRIZSONS, E. MANTOVANI, L. E.; AGUIAR, A. V. Relação entre altitude e temperatura: uma contribuição ao zoneamento climático no estado do Paraná. REA - Revista de estudos ambientais v.10, n. 1, p. 49-64, jan./jun. 2008.

GONÇALVES, L. F. H.; GUERRA, A. J. T. Movimento de Massa na Cidade de Petrópolis (Rio de Janeiro). In. GUERRA, A. J. T.; CUNHA, S. B. (Org.) Impactos Ambientais Urbanos no Brasil. 11 ${ }^{a}$ ed. - Rio de Janeiro, Bertrand Brasil, 2014. $418 \mathrm{pp}$.

HOFFMANN, T. C. P.; MENDONÇA, F.; GOUDARD, G.; Eventos climáticos extremos: inundações e gestão de riscos no Paraná. In. MENDONÇA, F. (Org.) Riscos Climáticos Vulnerabilidade e Resiliência Associados. Jundiai, Paco Editorial: 2014

LIBEMANN, B.; JONES, C.; CARVALHO, L. M. V.; Interannual Variability of Daily Extreme Precipitation Events in the State of São Paulo, Brazil. Journal of Climate, vol. 14, 2001.

MILANESI, M. A.; GALVANI, E. Efeito orográfico na ilha de São Sebastião. Revista Brasileira de Climatologia, N. 9 - JUL/DEZ/2011.

MONTEIRO, C. A. F. Clima e Excepcionalismo: conjecturas sobre o desempenho da atmosfera como fenômeno geográfico. Florianópolis: Edição da UFSC, 192. $233 p$.

MONTEIRO, C.A.F. Teoria e Clima Urbano. In MONTEIRO, C.A.F.; MENDONÇA, F. (org.) Clima Urbano. Ed. Contexto- São Paulo, 2003

MONTEIRO, C.A.F. O estudo geográfico do clima. Cadernos Geográfico/ Universidade Federal de Santa Catarina. Centro de Filosofia e Ciências Humanas. Departamento de Geociências- n.1, maio de 1999. Florianópolis, Imprensa Universitária, 1999.

NASCIMENTO JÚNIOR, L. Dinâmica pluviométrica e impacto das chuvas no estado do Paraná: A natureza dos eventos extremos. In SANT'ANNA NETO, J. L.; AMORIM, M. C. C. R.; SILVA, C.A. (Org.). Clima e Gestão do Território. Jundiaí, Paco Editorial: 201.

NIMER, E. Climatologia do Brasil. IBGE, 1989. Departamento de Recursos Naturais e Estudos Ambientais, Rio de Janeiro- RJ, $2^{a}$ ed., 421p.

Circulação Atmosférica do Brasil - Contribuição ao Estudo da Climatologia Dinâmica do Brasil - Revista Brasileira de Geografia, ano XXVIII, n.0 3, pp. 232-250 - IBG - Fundação IBGE - Rio de Janeiro. 1966.

Análise Dinâmica da Precipitação Pluviométrica na Região Serrana do Sudeste do Brasil - Especialmente na Serra das Araras. - Publicado na Revista Brasileira de Geografia - IBG - Fundação IBGE - Rio de Janeiro. 1971. 
Clima das Regiões Norte, Nordeste, Centro-Oeste e Sudeste do Brasil Publicado na 2.a edição da Série Geografia do Brasil - IBG - Fundação IBGE Rio de Janeiro. 1971

OLIVEIRA, D. E. Participação dos sistemas atmosféricos na gênese e ritmo das chuvas na bacia do rio Preto, MG/ RJ- Anos de 2006, 2007 e 2008. Dissertação (mestrado acadêmico) - 2016, 149 p.

REBOITA, M. S.; KRUSCHE, N.; AMBRIZZI, T.; ROCHA, R. P. Entendendo o tempo e o clima na América do Sul. TERRÆ DIDATICA 8(1):34-50, 2012.

ROE, G.H. Orographic Precipitation. Annu. Rev. Earth Planet. Sci. 2005. 33:64571 doi: 10.1146/annurev.earth.33.092203.122541.

ROLDÃO, A. F.; SANTOS, J. G.; OLIVEIRA, L. A. Correlação entre as variáveis climáticas (altitude, temperatura e precipitação) na mesorregião sul e sudeste de Minas Gerais-MG. REVISTA GEONORTE, Edição Especial 2, V.1, N.5, p.515 525, 2012

SENEVIRANTNES S. I., et al., 2012: Chapter 3: Changes in climate extremes and their Impacts on the Natural Physical Environment. In: SREX: Special Report on Managing the Risks of Extreme Events and Disasters to Advance Climate Change Adaptation [C. B. Field, et al. (eds.]. Cambridge University Press, Cambridge, United Kingdom and New York, NY, USA, pp.109-230

SILVEIRA, R. D. Risco climático, Vulnerabilidade socioespacial e eventos climáticos extremos relacionados ao calor e ao frio no estado do Rio Grande do Sul- Brasil. Presidente Prudente, maio de 2014. Tese de Doutorado em Geografia

STEPHENSON, D. B.; Definition, diagnosis, and origin of extreme weather and climate events. Climate Extremes and Society, ed. H. F. Diaz and R. J. Murnane. Published by Cambridge University Press. Cambridge University Press 2008

TAVARES, R. MENDONÇA, F. Ritmo Climático e Ritmo Social: pluviosidades e deslizamentos de terra na serra do mar- Ubatuba/ SP. In. MENDONÇA, F. (Org.) Riscos Climáticos: vulnerabilidade e resiliência associados. Jundiaí, Paco Editorial: 2014. 388p.

TERASSI, P. M. B.; GALVANI, E. O Efeito orográfico na serra do mar e o potencial erosivo das chuvas nas bacias hidrográficas do Ribeira e LitorâneaParaná. Revista Brasileira de Climatologia. Ano 13 - Vol. 21 - JUL/DEZ 2017.

AMORIM, M. C. C. T.; SANT'ANNA NETO, J. L.; MONTEIRO, A. Climatologia Urbana e Regional: Questões teóricas e estudos de caso. 1ed. São Paulo. Outras Questões, 2013.

SCHNEEBERGER, C.A.; FARAGO, L. A. Minimanual compacto de geografia do Brasil: teoria e prática. 1. ed. - São Paulo: Rideel, 2003. Editora Rideel

SELUCHI, M. E.; CHOU, S. C., 2009. Synoptic patterns associated with landslide events in the Serra do Mar, Brazil. Theor. Appl. Climatol, 98, 67-77.

SoUZA, M. L. Os Conceitos Fundamentais da Pesquisa Sócio-Espacial. $3^{a}$ d. - Rio de Janeiro: Bertarnd Brasil, 2016. 320p. 
ZANELLA, M. E.; OLÍMPIO J. L. S. Impactos pluviais, risco e vulnerabilidades em Fortaleza- CE. In. MENDONÇA, F. (Org.) Riscos Climáticos: vulnerabilidade e resiliência associados. Jundiaí, Paco Editorial: 2014. 388p. 